\title{
Determination of 18 biocides in both the dissolved and particulate fractions of urban and surface waters by HPLC-MS/MS
}

\author{
Claudia Paijens ${ }^{1,2}$, Bertrand Frère $^{2},{\text { Emilie } \text { Caupos }^{3}, \text { Régis Moilleron }^{3} \text {, and Adèle Bressy }}^{1, *}$ \\ ${ }^{1}$ Ecole des Ponts, Univ Paris Est Creteil, Leesu, Champs-sur-Marne, France \\ ${ }^{2}$ Laboratoire Central de la Préfecture de Police, Paris, France \\ ${ }^{3}$ Univ Paris Est Creteil, Ecole des Ponts, Leesu, Creteil, France \\ *corresponding author: adele.bressy@enpc.fr
}

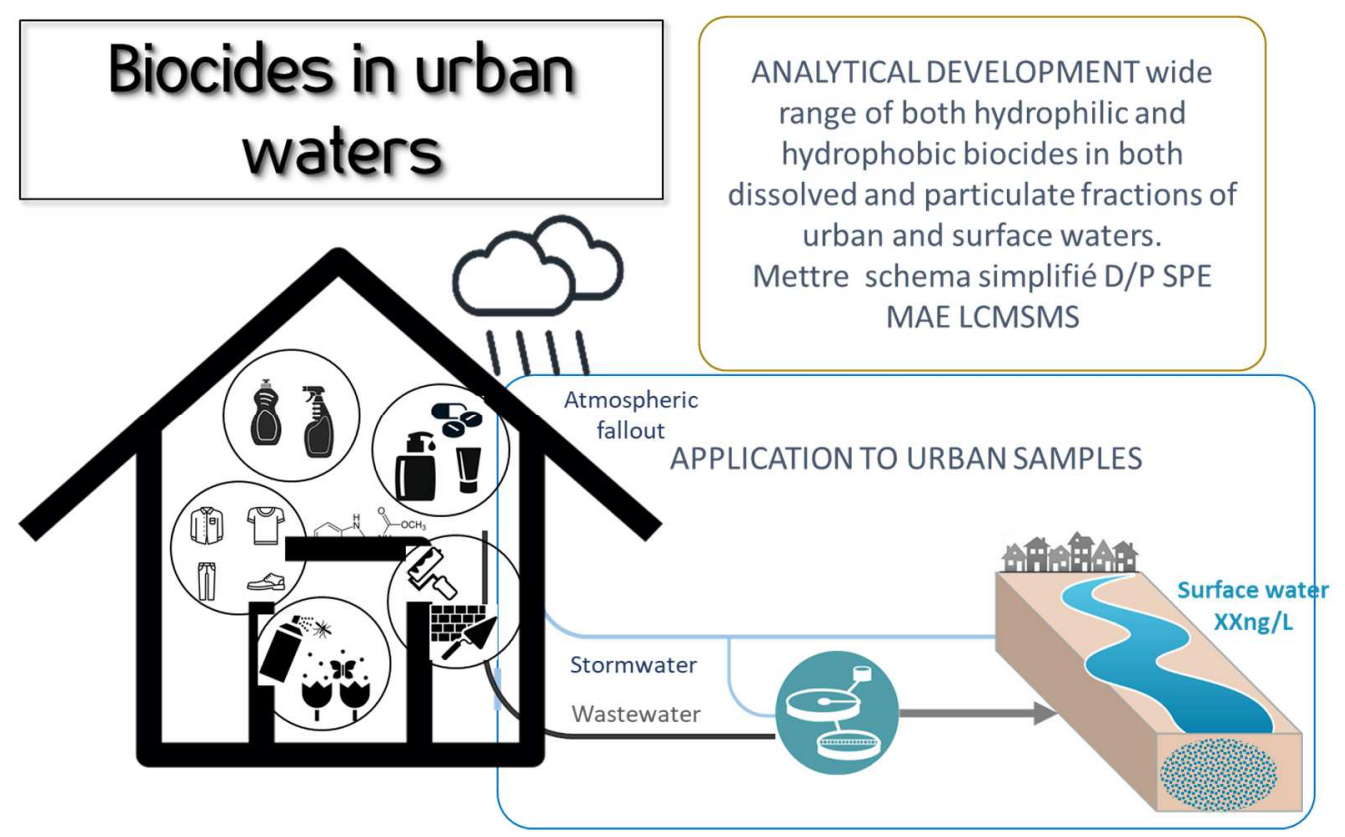

\begin{abstract}
A robust method is provided to analyze 18 hydrophilic and hydrophobic biocides in both dissolved and particulate fractions of five types of urban and surface waters using high performance liquid chromatography coupled to tandem mass spectrometry. The linearity, accuracy and intermediate precision were validated. The target biocides were enriched by solid phase extraction using Chromabond HR-X $200 \mathrm{mg}$ cartridges and eluted with methanol, ethyl acetate and dichloromethane. Suspended matter was extracted by microwave-assisted extraction in methanol and dichloromethane. Recoveries and variability (respectively $>75 \%$ and $<30 \%$ for most of the target biocides and matrices) made it possible to quantify biocides at trace level in all matrices. LOQs were in the range of ng/L in the dissolved fraction and in the range of $\mathrm{ng} / \mathrm{g} . \mathrm{dw}$ in the particulate fraction for most of the biocides and matrices and were generally lower than those reported in previous studies. The method was successfully applied to surface water, treated and untreated wastewater, combined sewer overflows, and stormwater providing, unique data in these matrices for some substances, in particular with respect to particle contamination. In urban waters, concentrations of most of the biocides ranged from 10 to $200 \mathrm{ng} / \mathrm{L}$. Diuron, isothazolinone and benzalkonium concentrations could reach $0.9,0.9$ and $20 \mu \mathrm{g} / \mathrm{L}$ respectively. In rivers, most of the biocides were measured at less than $10 \mathrm{ng} / \mathrm{L}$, but higher concentrations were observed for benzalkoniums (up to $200 \mathrm{ng} / \mathrm{L}$ ) or after rain events, which indicates biocide transfer from urban surfaces into the aquatic environment during wet weather.
\end{abstract}

\section{Keywords}

Biocides, dissolved and particulate fractions, SPE, microwave assisted extraction, urban waters, surface waters 


\section{Introduction}

In recent years, biocidal substances in the aquatic environment have received an increasing attention because of (i) their many uses especially in urban areas (Bester et al. 2008; Bollmann et al. 2014b; Paijens et al. 2020; Wieck et al. 2018), (ii) their transfer into the aquatic environment via wastewater or stormwater discharges (Bollmann et al. 2014a; Burkhardt et al. 2011; Juksu et al. 2019; Wicke et al. 2015), and (iii) their negative effect on aquatic organisms (Mohr et al. 2008; Vermeirssen et al. 2018). Indeed, biocides are toxic and may cause long-term adverse effects to aquatic ecosystems even at low concentrations, such as endocrine disruption in zebrafish larvae (Jiang et al., 2015) or behavioural disturbance in zebrafish embryos (Andrade et al., 2016). The predicted no effect concentrations (PNEC) of these substances are in the range of $\mathrm{ng} / \mathrm{L}: 1 \mathrm{ng} / \mathrm{L}$ for cybutryn (Burkhardt et al., 2011), $8 \mathrm{ng} / \mathrm{L}$ for dichloro-octylisothiazolinone (Burkhardt et al., 2009), and $40 \mathrm{ng} / \mathrm{L}$ for benzalkonium C12 (Uhl et al., 2005) for instance. This work focuses on 18 biocides, which were previously prioritized (Paijens et al. 2019) according to (i) their use in urban areas, and especially as preservatives in building materials such as paints, renders, wood or bitumen membranes, (ii) their emission into runoff and the receiving waters, and (iii) their risk for aquatic organisms: diuron, isoproturon, methylisothiazolinone (MIT), benzisothiazolinone (BIT), chloromethylisothiazolinone (CMIT), octylisothiazolinone (OIT), dichloro-octylisothiazolinone (DCOIT), benzalkonium compounds (BZK C12-C16), terbutryn, cybutryn (irgarol 1051), terbuthylazine, carbendazim, iodopropynyl butylcarbamate (IPBC), thiabendazole, tebuconazole and mecoprop. A state-of-the-art review (Paijens et al. 2020) identified many knowledge gaps, preventing the full assessment of the risks associated with biocides originating from buildings. Most of these biocides are also used as plant protection products and thus have been monitored in rural areas but more rarely in urban waters (Paijens et al. 2020). For other compounds not used as pesticides (isothiazolinones, benzalkonium compounds, IPBC), data in receiving and urban waters are scarcer (Paijens et al. 2020). A few studies have shown that these substances can be emitted at high concentrations in building runoff (Bollmann et al. 2016; Bollmann et al. 2017; Burkhardt et al. 2011, 2012; Van de Voorde et al. 2012). Runoff concentrations and cumulative emissions have been reported in Paijens et al. (2020). For example, diuron was measured between 1 and $25 \mathrm{mg} / \mathrm{L}$ (Burkhardt et al. 2012; Bollmann et al. 2016) and benzalkonium compounds between 0.04 and $27 \mathrm{mg} / \mathrm{L}$ (Van de Voorde et al. 2012). However, their transfer to the aquatic environment and the contribution of building materials to the contamination of receiving waters by biocides have been little studied (Paijens et al. 2020). Although these substances are also used in domestic products such as detergents, cosmetics, and textiles or as insecticides (Bester et al. 2008; Wieck et al. 2016), their urban sources have been overlooked in terms of health and environmental risk assessment (Merel et al. 2018; Paijens et al. 2020; Wieck et al. 2016). So far, biocides are still poorly regulated in the aquatic environment, and are therefore not included in monitoring programs (Dulio et al. 2015; Geissen et al. 2015). It is therefore important to address the lack of knowledge about their dynamics in urban waters and to prioritize emission pathways into the aquatic media.

Several multi-residue analytical procedures have been reported in the literature for the determination of biocides and pesticides (Bester and Lamani 2010; Chen et al. 2012; Cotton et al. 2016; Moschet et al. 2014; Singer et al. 2010; Van de Voorde et al. 2012; Wick et al. 2010; Wieck et al. 2018). However only Wieck et al. (2018) have considered hydrophilic and cationic/hydrophobic biocides, such as isothiazolinones (excepting MIT) and benzalkonium compounds (only BZK C12). These methods are based on high performance liquid chromatography coupled to tandem mass spectrometry (HPLC-MS/MS). Most of the currently available methods for dissolved extraction are based on solid phase extraction (SPE). Polymeric phases such as divynylbenzene (Hydrophobic DVB, Baker), polystyrene-divinylbenzene (Strata-X from Phenomenex or Chromabond HR-X from MachereyNagel) or vinylpyrrolidinone-divinylbenzene (Oasis HLB, Waters), are widely used for all the selected compounds, as they provide mixed retention (Bester and Lamani 2010; Chen et al. 2012; Singer et al. 2010; Wieck et al. 2018). Benzalkonium cations can be extracted using a cationic exchange phase (Van de Voorde et al. 2012). Cartridges that combine several phases are also used for multi-residue analysis (Moschet et al. 2014; Rafoth et al. 2007). Concerning the particulate fraction, most studies focus on soils (Chitescu et al. 2012; Hildebrandt et al. 2007; Huang et al. 2018; Shah et al. 2011; Stipičević et al. 2015) or sediments (Kalogridi et al. 2014; Masiá et al. 2015; Sánchez-Rodríguez et al. 2011) and only on a limited number of compounds. To the best of the authors' knowledge, only three studies have investigated and therefore pointed out the contamination of suspended matter by biocides (Östman et al. 2017; Van de Voorde et al. 2012; Wieck et al. 2018). Benzalkoniums were measured in stormwater and wastewater particles by Van de Voorde et al. (2012) and Östman et al. (2017) using microwave assisted extraction (MAE) or bead beater with zirconium/silica beads, and 14 biocides were analyzed by Wieck et al. (2018) using ultrasounds.

The aim of this study was to develop a sensitive and robust method for the quantification of the 18 targeted biocides in both dissolved and particulate fractions of a wide range of matrices: rainwater, stormwater, combined sewer overflows (CSOs), treated and untreated wastewater, and surface waters. The first objective was to optimize a suitable method for a wide range of matrices and concentrations, with detection and quantification limits in surface 
waters below predicted no effect concentrations (PNECs) in order to assess the environmental risk. The second objective was to apply the validated method to real samples in order to assess the contamination of urban waters and the respective contribution of dry and wet weather water discharges to the pollution of the receiving aquatic environment.

\section{Materials and methods}

\subsection{Chemicals and reagents}

Information about the 18 targeted compounds are listed in the electronic supplementary material (ESM) Table S1. All standards of high purity (> 90\%) were commercially available. Carbendazim, IPBC, tebuconazole, terbutryn, thiabendazole, 2-methyl-4-isothiazolin-3-one, 4,5-dichloro-2-n-octylisothiazol-3(2H)-one and 5-chloro-2-methyl4-isothiazolin-3-one were purchased from A2S (France). Cybutryn, isoproturon, mecoprop, terbuthylazine, 1,2benzisothiazol-3(2H)-one, 2-octylisothiazol-3(2H)-one and the isotope labelled standard isoproturon-d6 was obtained from Dr. Ehrenstorfer (Germany). Three benzalkonium chlorides (benzyldimethyldodecyl ammonium chloride $\mathrm{C} 12$, benzyldimethyltetradecyl ammonium chloride $\mathrm{C} 14$, and benzyldimethylhexadecyl ammonium chloride C16) were purchased from Sigma Aldrich (France). The isotope-labelled standards terbuthylazine-d5 and mecoprop-d3 were obtained from CDN Isotopes (Canada).

HPLC-grade methanol (MeOH), dichloromethane (DCM), ethyl acetate (EtAc) and formic acid (HCOOH) were purchased from ThermoFisher Scientific (France). Deionized water was produced by an Elix Essential 3 system and ultrapure (UP) water was produced by Milli-Q IQ 7000 system, both from Merck Millipore (France).

Individual stock solutions of all compounds were prepared in $\mathrm{MeOH}$ at $1 \mathrm{mg} / \mathrm{mL}$ except for $\mathrm{MIT}(20 \mathrm{mg} / \mathrm{mL})$, terbuthylazine $(0.25 \mathrm{mg} / \mathrm{mL}$ ), carbendazim (in acetone at $0.1 \mathrm{mg} / \mathrm{mL}$ ), and terbuthylazine-d5 (in acetone at $1 \mathrm{mg} / \mathrm{mL}$ ). Standard mixture solutions were prepared in $\mathrm{MeOH}$ at $5 \mathrm{mg} / \mathrm{L}, 50 \mu \mathrm{g} / \mathrm{L}$ and $10 \mu \mathrm{g} / \mathrm{L}$. Internal standard (IS) mixture solution (isoproturon-d6, mecoprop-d3 and terbuthylazine-d5) was prepared in $\mathrm{MeOH}$ at $10 \mathrm{mg} / \mathrm{L}$. All solutions were stored in $15 \mathrm{~mL}$ amber glass bottles and kept at $4{ }^{\circ} \mathrm{C}$.

\subsection{Sample collection and preparation}

\subsubsection{Sample collection}

Surface water samples were collected upstream of the Paris conurbation in the Marne River, in the middle of the channel and at around one meter deep (5 L grab sample). Dry and wet atmospheric depositions were collected using an amber glass bottle $(20 \mathrm{~L})$ connected to a $1 \mathrm{~m}^{2}$ stainless pyramidal funnel located on the roof of the Central Laboratory of the Police Prefecture. Wastewater treatment plant (WWTP) influents and effluents were collected from the Seine centre WWTP ( $24 \mathrm{~h}$ composite samples). CSOs samples (mix of wastewater and stormwater) were collected in Paris (flow-dependent samples). Stormwater was sampled in an underground stormwater storage pond in Paris (time-dependent samples).

\subsubsection{Preparation of samples}

In order to remove any traces of organic impurities, all glassware was successively hand-washed with detergent $\left(24 \mathrm{~h}\right.$ ), rinsed with tap water and deionized water, and heated at $500{ }^{\circ} \mathrm{C}$ for $2 \mathrm{~h}$. Samples were filtered within $24 \mathrm{~h}$ after sampling through $0.7 \mu \mathrm{m}$ glass fiber filters $\left(\mathrm{GF} / \mathrm{F}\right.$, Whatman, UK) previously heated at $500{ }^{\circ} \mathrm{C}$ for $2 \mathrm{~h}$. In order to obtain enough particles, $250 \mathrm{~mL}$ of CSO sample, $300 \mathrm{~mL}$ of stormwater, $400 \mathrm{~mL}$ of wastewater, $1 \mathrm{~L}$ of WWTP effluents, and $2 \mathrm{~L}$ of surface waters and rainwater were filtered. The dissolved fraction was stored in a glass bottle at $4{ }^{\circ} \mathrm{C}$ and extracted within $48 \mathrm{~h}$ after sampling. Before extraction, the sample $\mathrm{pH}$ was adjusted to 2.5 with $0.1 \%(\mathrm{v} / \mathrm{v})$ of $\mathrm{HCOOH}(98-100 \%)$. The GF/F filter containing the particulate fraction was frozen and then freeze-dried for $24 \mathrm{~h}$. The filter was then stored in a desiccator until its extraction.

\subsection{Sample extraction}

\subsubsection{Dissolved fraction}

The dissolved fraction was extracted by SPE on a semi-automatic device, AutoTrace (AT280) from Caliper Life Sciences (France). The protocol is summarized in ESM Table S2. Samples were extracted on a Chromabond HR$\mathrm{X}$ cartridge (200 mg, $6 \mathrm{~mL}$ ) from Macherey-Nagel (France). First, the cartridge was successively conditioned with $5 \mathrm{~mL}$ of DCM, $10 \mathrm{~mL}$ of EtAc, $10 \mathrm{~mL}$ of $\mathrm{MeOH}$, and $10 \mathrm{~mL}$ of acidified UP water (pH 2.5). The sample was then 
loaded onto the cartridge: $100 \mathrm{~mL}$ for CSOs and wastewater, $200 \mathrm{~mL}$ for treated wastewater and stormwater, and $500 \mathrm{~mL}$ for surface waters and rainwater. After loading, the cartridge was washed with $2 \mathrm{~mL}$ of acidified UP water and dried under nitrogen flow. The compounds were then successively eluted with $6 \mathrm{~mL}$ of MeOH, $3 \mathrm{~mL}$ of EtAc, and $2 \mathrm{~mL}$ of DCM. The extract was collected in a $15 \mathrm{~mL}$ amber glass bottle and stored at $-8{ }^{\circ} \mathrm{C}$ prior to analysis. Before injection, the solvents were evaporated under a nitrogen flow up to $500 \mu \mathrm{L}$, corresponding to the volume of acidified UP water added before evaporation. The extract was then completed to $1 \mathrm{~mL}$ with the mobile phase in order to obtain $80 \%$ acidified UP water and $20 \%$ acidified $\mathrm{MeOH}$ in the final extract. Lastly, the extract was filtered through a $0.2 \mu \mathrm{m}$ syringe filter and $5 \mu \mathrm{L}$ of injection IS solution were added.

\subsubsection{Particulate fraction}

Particles were extracted using a closed glassware Multiwave 3000 microwave from Anton Paar (France). The protocol is described in ESM Table S3. First, the filter containing the particles was cut into small pieces and introduced into a PTFE tube. The sample was then extracted by microwaves and using $20 \mathrm{~mL}$ of $\mathrm{MeOH} / \mathrm{DCM}$ $(60 / 40, \mathrm{v} / \mathrm{v})$. The temperature program was set as follows: rise in temperature up to $100{ }^{\circ} \mathrm{C}$ for $5 \mathrm{~min}$, then temperature kept at $100{ }^{\circ} \mathrm{C}$ for $10 \mathrm{~min}$, and cooling. The extract was then filtered through a pleated filter previously dampened with $4 \mathrm{~mL}$ of extraction solvent and collected in a flat-bottom flask. After filtration, the filter was rinsed with $4 \mathrm{~mL}$ of extraction solvent in order to avoid any losses. The sample was then extracted a second time with the same protocol and both extracts were combined. The solvent was then pre-evaporated with a Rotavapor from Büchi (France) to $4 \mathrm{~mL}$. The final volume was transferred to a $15 \mathrm{~mL}$ amber glass bottle and the flat-bottom flask was rinsed with $2 \mathrm{~mL}$ of solvent. The extract was stored at $-8{ }^{\circ} \mathrm{C}$ and was prepared for injection in the same was as SPE extracts.

\subsection{Analysis by HPLC-MS/MS}

After extraction, the analysis was conducted by Ultra Performance Liquid Chromatography (Waters Acquity®) coupled with triple quadripole mass spectrometry (Waters TQD®). Chromatographic separation was performed on a 100 x $2.1 \mathrm{~mm}$ i.d. $(1.7 \mu \mathrm{m})$ Acquity UPLC® HSS T3 column with its corresponding VanGuard ${ }^{\mathrm{TM}}$ pre-column $(5 \times 2.1 \mathrm{~mm}, 1.7 \mu \mathrm{m})$ from Waters. The flow rate was set at $0.4 \mathrm{~mL} / \mathrm{min}$ and the column temperature maintained at $40{ }^{\circ} \mathrm{C}$. The injection volume was $10 \mu \mathrm{L}$. The mobile phase contained (A) MeOH acidified with $\mathrm{HCOOH}(0.1 \%$ in volume) and (B) UP water acidified with $\mathrm{HCOOH}(0.1 \%$ in volume). The gradient program was: $5 \% \mathrm{~B}$ at $0 \mathrm{~min}$ and held for $2 \mathrm{~min}$, increased to $20 \% \mathrm{~B}$ at $2 \mathrm{~min}$, increased to $100 \% \mathrm{~B}$ in $17 \mathrm{~min}$ and held for $10 \mathrm{~min}$, decreased to $5 \% \mathrm{~B}$ in $1 \mathrm{~min}$ and held for $5 \mathrm{~min}$ for column equilibration before the next injection.

Ionization was performed with an ESI source in positive mode for all targeted biocides except for mecoprop, which is only ionized in negative mode. The acquisition was achieved in multiple reaction monitoring. The MS parameters are reported in ESM Table S4. For all biocides, precursor ions were the protonated or deprotonated molecular ion. Compound identification was based on the retention time (RT; $\pm 0.05 \mathrm{~s}$ ) and the selected two MS/MS transitions serving as quantifier (the most intense) and qualifier. Information relating to mass transitions, which were optimized by direct infusion, is reported in Table 1. The chromatograms obtained are shown in ESM (Fig. S1, Fig. S2 and Fig. S3).

\subsection{Quantification, quality control and method validation}

\subsubsection{Quantification and quality control}

Three isotopically-labelled IS were used to quantify the targeted compounds in order to compensate for any matrix effects or experimental issues. They were added before injection. Mecoprop-d3 was used for the quantification of mecoprop, which is the only compound ionized in negative mode. Other biocides were distributed between the two other internal standards in order to obtain the best linearity. Isoproturon-d6 was used for the quantification of BIT, diuron, IPBC, isoproturon and OIT. Terbuthylazine-d5 was used for the quantification of benzalkonium compounds (C12-C16) carbendazim, CMIT, DCOIT, cybutryn, MIT, tebuconazole, terbuthylazine, terbutryn, thiabendazole. Calibration curves were obtained from spiked standards in mobile phase $(\mathrm{A} / \mathrm{B}, 80 / 20$, v/v) at 0.05 , $0.1,0.25,0.5,0.75,1,2.5,5,10,25,75,150,250 \mu \mathrm{g} / \mathrm{L}$ and $5 \mu \mathrm{L}$ of the internal standard solution was added (final concentration of $50 \mu \mathrm{g} / \mathrm{L}$ ). The calibration curves were produced by calculating the ratio between each standard area and its corresponding IS area, using quantification transitions. Blanks were injected every 5-6 samples and a $10 \mu \mathrm{g} / \mathrm{L}$-control was injected at the beginning of the analytical sequence, at mid-sequence and at the end. 
Table 1 Retention times and information relating to mass transitions for the 18-targeted biocides and the three IS

\begin{tabular}{|c|c|c|c|c|c|c|c|c|}
\hline \multirow{2}{*}{ Biocides } & \multirow{2}{*}{$\begin{array}{l}\text { Retention } \\
\text { time (min) }\end{array}$} & \multicolumn{2}{|c|}{ Optimal voltages } & \multirow{2}{*}{$\begin{array}{c}\begin{array}{c}\text { Precursor } \\
\text { ion }\end{array} \\
\mathbf{m} / \mathbf{z}\end{array}$} & \multicolumn{2}{|c|}{ Quantification } & \multicolumn{2}{|c|}{ Confirmation } \\
\hline & & $\begin{array}{c}\text { Capillary } \\
(\mathbf{k V})\end{array}$ & $\begin{array}{c}\text { Cone } \\
\text { (V) }\end{array}$ & & $\mathbf{m} / \mathbf{z}$ & $\begin{array}{l}\mathrm{CE} \\
(\mathrm{eV})\end{array}$ & $\mathbf{m} / \mathbf{z}$ & $\begin{array}{c}\mathrm{CE} \\
(\mathrm{eV})\end{array}$ \\
\hline MIT & 2.12 & 2.5 & 44 & 115.98 & 100.91 & 22 & 58.02 & 20 \\
\hline Carbendazim & 4.36 & 0.6 & 32 & 192.09 & 160.05 & 18 & 132.04 & 30 \\
\hline CMIT & 4.75 & 0.5 & 40 & 149.97 & 115.96 & 20 & 57.9 & 24 \\
\hline Thiabendazole & 4.99 & 0.4 & 45 & 202.02 & 175.05 & 24 & 131.01 & 32 \\
\hline BIT & 5.98 & 2.5 & 48 & 152 & 108.88 & 21 & 104.94 & 22 \\
\hline IPBC & 10.44 & 0.6 & 28 & 281.94 & 164.81 & 20 & 56.98 & 10 \\
\hline Isoproturon & 10.67 & 3.5 & 32 & 207.17 & 71.96 & 18 & 165.06 & 16 \\
\hline Diuron & 10.78 & 3.5 & 38 & 233.05 & 71.97 & 24 & 46.03 & 16 \\
\hline Terbutryn & 10.82 & 0.7 & 38 & 242.13 & 186.04 & 18 & 90.93 & 26 \\
\hline Cybutryn & 11.41 & 0.4 & 38 & 254.15 & 198.07 & 18 & 82.97 & 30 \\
\hline Terbuthylazine & 12.08 & 0.5 & 28 & 230.15 & 174.06 & 16 & 96.01 & 28 \\
\hline Mecoprop & 12.11 & 2.4 & 28 & 212.99 & 140.92 & 12 & 70.93 & 14 \\
\hline OIT & 12.94 & 0.6 & 32 & 214.09 & 101.38 & 14 & 56.98 & 18 \\
\hline $\begin{array}{c}\text { Benzalkonium } \\
\text { C12 } \\
\end{array}$ & 13.6 & 0.5 & 55 & 304.34 & 90.99 & 28 & 212.3 & 22 \\
\hline Tebuconazole & 13.8 & 0.7 & 36 & 308.18 & 69.94 & 2 & 124.99 & 32 \\
\hline $\begin{array}{c}\text { Benzalkonium } \\
\text { C14 }\end{array}$ & 14.8 & 0.5 & 40 & 332.36 & 90.95 & 30 & 240.3 & 22 \\
\hline DCOIT & 15.53 & 0.6 & 32 & 282.89 & 169.89 & 14 & 57.04 & 18 \\
\hline $\begin{array}{c}\text { Benzalkonium } \\
\text { C16 } \\
\end{array}$ & 15.76 & 0.5 & 48 & 360.39 & 90.95 & 30 & 268.28 & 24 \\
\hline Isoproturon-d6 & 10.63 & 0.6 & 32 & 213.18 & 77.99 & 18 & 51.99 & 18 \\
\hline $\begin{array}{l}\text { Terbuthylazine- } \\
\text { d5 }\end{array}$ & 12.05 & 0.5 & 36 & 235.13 & 179 & 18 & 100.99 & 29 \\
\hline Mecoprop-d3 & 12.08 & 2.2 & 30 & 216.09 & 143.89 & 14 & 70.86 & 18 \\
\hline
\end{tabular}

\subsubsection{Determination of HPLC-MS/MS performances}

System repeatability was evaluated from seven replicate injections of solutions at $10 \mu \mathrm{g} / \mathrm{L}$ and $75 \mu \mathrm{g} / \mathrm{L}$ containing all selected biocides. Relative standard deviations (RSD) were calculated for both concentrations. To evaluate the linearity and the intermediate precision of the HPLC-MS/MS method, the calibration curve was repeated five times by changing at least one parameter (day of analysis, preparation of the solutions or mobile phase). Linearity was validated in accordance with the French norm "NF T-90-210": for each point of the curve, the concentration was re-calculated by using the peak area and that of its corresponding IS. The linearity was validated if the error between the value calculated and the corresponding theoretical value was below $20 \%$. Instrumental limit of detection $\left(\mathrm{LOD}_{\mathrm{i}}\right)$ was determined as the lowest concentration for which both quantification and confirmation transitions were detected. $\mathrm{LOQ}_{\mathrm{i}}$ was defined as the concentration from which the analytical method gives a guarantee that RSD was below a targeted value, between $10 \%$ and 35\% depending on the compound (Mompelat et al. 2015; Slimani et al. 2017; Vial et al. 2003).

\subsubsection{Determination of recoveries, $L O D$ and $L O Q$ in the dissolved fraction}

To validate the overall method, including extraction step, samples were spiked at least three times at three different concentrations (given in the Table S5 in ESM) with the standard mixture solutions. Relative recoveries were determined using the ratio between the measured concentration in the extract (concentration in spiked sample concentration in sample without spiking) and the theoretical value. To determine biocide concentrations in real 
samples, each measured concentration was corrected by the recovery in the corresponding matrix. LOD $_{\mathrm{D}} \mathrm{Was}_{\mathrm{S}}$ calculated in accordance with equation 1. Similarly, LOQD was calculated using $\mathrm{LOQ}_{i}$.

$$
L O D_{D}=\frac{L O D_{i}}{V_{S}} \times \frac{100}{R} \times V_{E}
$$

Equation 1 Calculation of the LOD in the dissolved fraction, where $L O D_{i}$ is the instrumental LOD (ng/L), $V_{S}$ the sample volume $(\mathrm{mL}), R$ the recovery $(\%)$ and $V_{E}$ the final volume of the extract (always $1 \mathrm{~mL}$ )

\subsubsection{Determination of recoveries, $L O D$ and $L O Q$ in the particulate fraction}

Regarding the particulate fraction, the spiking method is not appropriate. Spiking compounds are more easily mobilized than those absorbed into particles in real samples (Miege et al. 2003). Also, no certified samples are available. Thus, in most studies, standards are added to the extraction solvent and are not linked to particles. In this case, the recoveries obtained may not be representative. On the basis of Geara-Matta's (2012) validation method and in order to take into account substance-particle interactions, six wastewater samples (matrix containing the most suspended solids, SS) were successively extracted four times and each fraction was separately analyzed. Recoveries of the first two fractions $(\mathrm{F} 1+\mathrm{F} 2)$ were calculated with respect to the total quantity extracted in the four fractions. $\mathrm{LOD}_{\mathrm{P}}$ was calculated in accordance with equation 2. Similarly, LOQP were calculated using to $\mathrm{LOQ}_{\mathrm{i}}$.

$$
L O D_{P}=\frac{L O D_{i}}{m_{S S}} \times \frac{100}{R} \times V_{E}
$$

Equation 2 Calculation of the LOD in the particulate fraction, where $L O D_{i}$ is the instrumental LOD in (ng/g.dw dry weight), $m_{s s}$ the quantity of suspended solid (g), $R$ the recovery (\%) and $V_{E}$ the final volume of the extract (always $1 \mathrm{~mL}$ )

\subsubsection{Determination of matrix effects}

Matrix effects were determined for the three IS in all samples by comparing peak areas in mobile phase $\left(A_{M P}\right)$ and in the extracts $\left(A_{E}\right)$ in accordance with equation 3 . For both, $5 \mu \mathrm{L}$ of a $10 \mathrm{mg} / \mathrm{L}$ solution of IS were added to $1 \mathrm{~mL}$ of mobile phase (acidified UP water/acidified $\mathrm{MeOH}, 80 / 20$ ) or to the $1 \mathrm{~mL}$ extract.

$$
\text { Matrix effect }(\%)=\left(\frac{A_{E}}{A_{M P}}-1\right) \times 100
$$

Equation 3 Calculation of matrix effects where $A_{M P}$ is the area of the IS in the mobile phase and $A_{E}$ the area of the IS in the extract

\section{Results and discussion}

\subsection{Method development}

\subsubsection{UPLC-MS/MS optimization}

Two columns were compared: (i) $100 \times 2.1 \mathrm{~mm}$ i.d. $(1.7 \mu \mathrm{m})$ Acquity UPLC® BEH C18, selected for its highly apolar nature, and (ii) $100 \times 2.1 \mathrm{~mm}$ i.d. $(1.7 \mu \mathrm{m})$ Acquity UPLC® HSS T3, selected for its mixed retentive properties, both from Waters. The HSS T3 column was finally chosen for the following reasons: (i) it allows slightly better retention of the most polar compound MIT (RT of $2.13 \mathrm{~min}$ ) compared with the BEH C18 column (RT of $1.49 \mathrm{~min}$ ); (ii) the RT of the last compounds, BZK C16, is almost 5 min lower, which reduces the analysis time; (iii) for compounds with close RT, a slightly better separation is observed on the HSS T3 column (ESM Fig. S4).

The operating conditions for MS (capillary and cone voltages, collision energy, acquisition time and product ions) were optimized for each compound to maximize the response. They are reported in Table 1.

\subsubsection{Optimization of SPE}

Two different SPE cartridges were tested: Chromabond HR-X (6 mL, $200 \mathrm{mg}$, Macherey-Nagel), which is made of a divinylbenzene-polystyrene copolymer and with a specific surface area of $1000 \mathrm{~m}^{2} / \mathrm{g}$ (Wieck et al. 2018), and 
Oasis HLB (6 mL, $200 \mathrm{mg}$, Waters), which is made of a divinylbenzene-vinyl pyrrolidinone copolymer and with a specific surface area of $810 \mathrm{~m}^{2} / \mathrm{g}$ (Chen et al. 2012; Cotton et al. 2016; Wick et al. 2010). UP water (100 mL) was spiked at $100 \mathrm{ng} / \mathrm{L}$ and loaded on both cartridges. Six replicates were extracted following the protocol reported in ESM Table S2. Recoveries and RSDs were compared (Fig. 1) and statistical tests were performed according to the scheme given in ESM Fig. S5. Fig. 1 shows recoveries between $70 \%$ and $90 \%$ on both cartridges for most of the biocides, with RSD between $1 \%$ and $15 \%$, but a few issues were observed. Lower recoveries were obtained for MIT, which is a small hydrophilic molecule. It is therefore eluted by the sample water. A more hydrophilic stationary phase or a cartridge with a higher specific surface area and phase quantity would have been more appropriate for MIT but not suitable for hydrophobic compounds such as benzalkoniums. Bester and Lamani (2010) reported very low recoveries for MIT (5\%) in tap water with a similar cartridge (Hydrophobic DVB, Baker) for similar reasons. Lower recoveries were also obtained for benzalkonium cations. These compounds have long carbon chains and might remain sorbed on the cartridge or on the analytical system. A cationic exchange cartridge such as Strata-X® CW (Phenomenex) would have been more appropriate (Van de Voorde et al. 2012) but not suitable for the other targeted biocides. ESM Table S6 reports the results of the statistical tests. Recoveries were significantly higher with the Chromabond HR-X cartridge for CMIT, MIT, cybutryn, terbuthylazine, thiabendazole and BZK C14, probably because of a higher specific surface area. Also, variability slightly decreased with this cartridge (RSDs from 1\% to 53\%) compared with the Oasis HLB cartridge (RSD from 5\% to 97\%), especially for benzalkonium compounds. Therefore, the Chromabond HR-X cartridge was chosen.

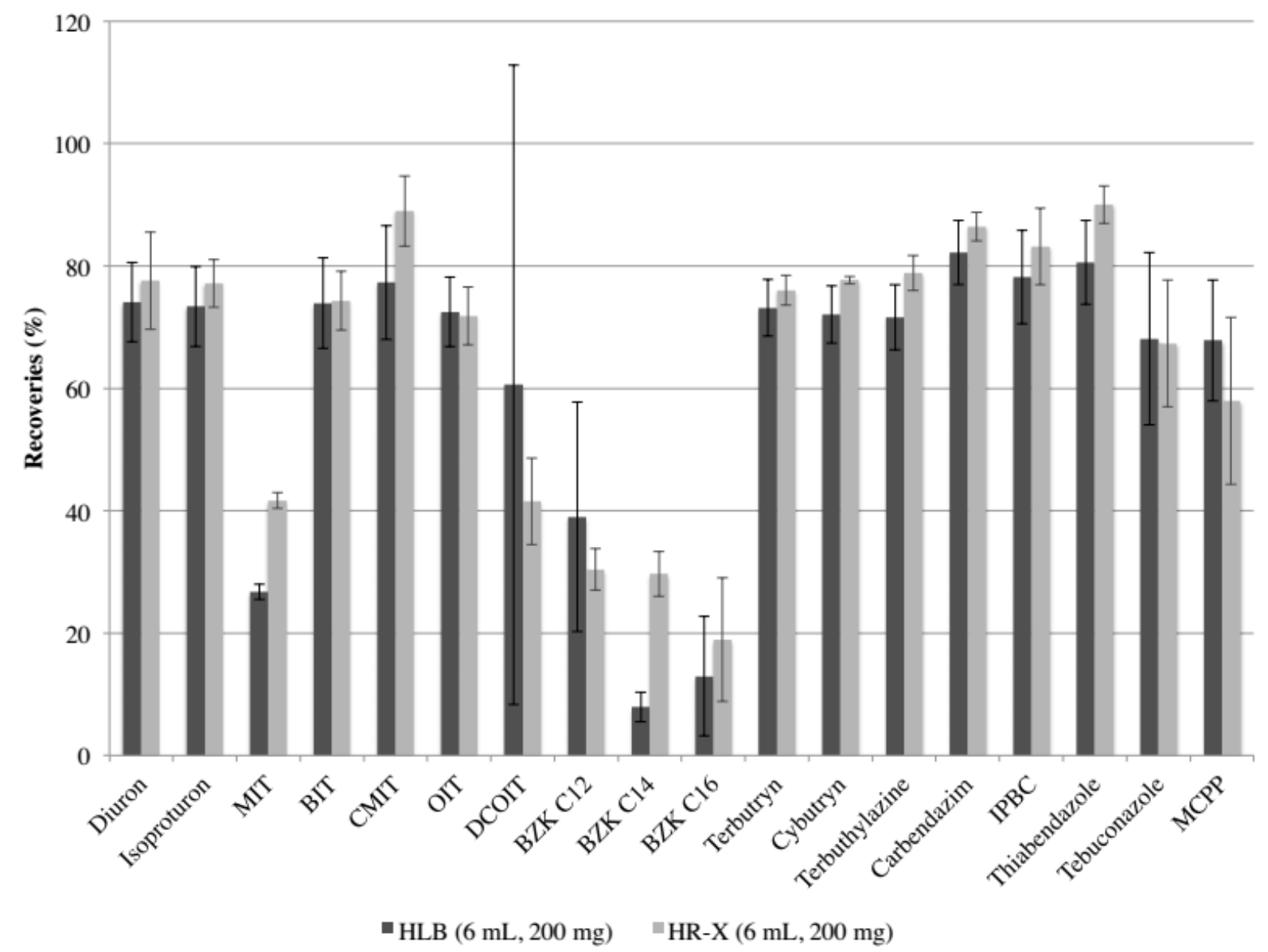

Fig. 1 Recoveries of the targeted biocides on the two tested SPE cartridges (mean \pm standard deviation)

To determine whether DCM was necessary for the elution, and thus to reduce solvent consumption, three spiked solutions of UP water $(100 \mathrm{~mL}$ at $100 \mathrm{ng} / \mathrm{L})$ were extracted following the protocol reported in Table S3, except for the elution. Compounds were eluted with (i) $6 \mathrm{~mL}$ of MeOH, $3 \mathrm{~mL}$ of EtAc, and $2 \mathrm{~mL}$ of DCM or (ii) $6 \mathrm{~mL}$ of $\mathrm{MeOH}$ and $3 \mathrm{~mL}$ of EtAc. For most of the biocides, elution without DCM led to slightly higher recoveries but they remained similar (ESM Fig. S6): less than 5\% of difference was observed for most of the biocides. Higher differences were obtained for DCOIT (recovery of $42 \%$ with DCM vs. $68 \%$ without) and tebuconazole (recovery of $64 \%$ with DCM vs. $79 \%$ without). However, a higher variability was observed for DCOIT and mecoprop without DCM (RSD of $47 \%$ and $33 \%$ respectively) compared with the elution with DCM (RSD of $17 \%$ and $8 \%$ 
respectively). A 10-20\% increase in recoveries was obtained with DCM for BIT, CMIT, BZK C14 and C16. Consequently, DCM was kept as the third elution solvent.

\subsubsection{Optimization of $M A E$}

To optimize the MAE procedure, virgin glass fiber filters were spiked with $200 \mu \mathrm{L}$ of a solution containing all the targeted biocides at $50 \mu \mathrm{g} / \mathrm{L} \mathrm{(10} \mathrm{ng} \mathrm{on} \mathrm{the} \mathrm{filter,} \mathrm{ESM} \mathrm{Fig.} \mathrm{S7)} \mathrm{and} \mathrm{extracted} \mathrm{according} \mathrm{to} \mathrm{the} \mathrm{protocol} \mathrm{described}$ in ESM Table S3 by varying some parameters. Four different extraction temperatures were tested: $60{ }^{\circ} \mathrm{C}, 80^{\circ} \mathrm{C}$, $100^{\circ} \mathrm{C}$ and $120^{\circ} \mathrm{C}$. Three replicates were extracted for each temperature. Recoveries (with respect to the spiked values) at different temperatures are reported in Fig. 2. For most of the biocides, the optimal extraction temperature was $100{ }^{\circ} \mathrm{C}$ : recoveries were between $60 \%$ and $90 \%$ and RSDs were below $20 \%$. However, low recoveries (from undetected to $40 \%$ ) were obtained for benzalkonium compounds and IPBC. Thus, a longer temperature plateau and another extraction solvent were tested.

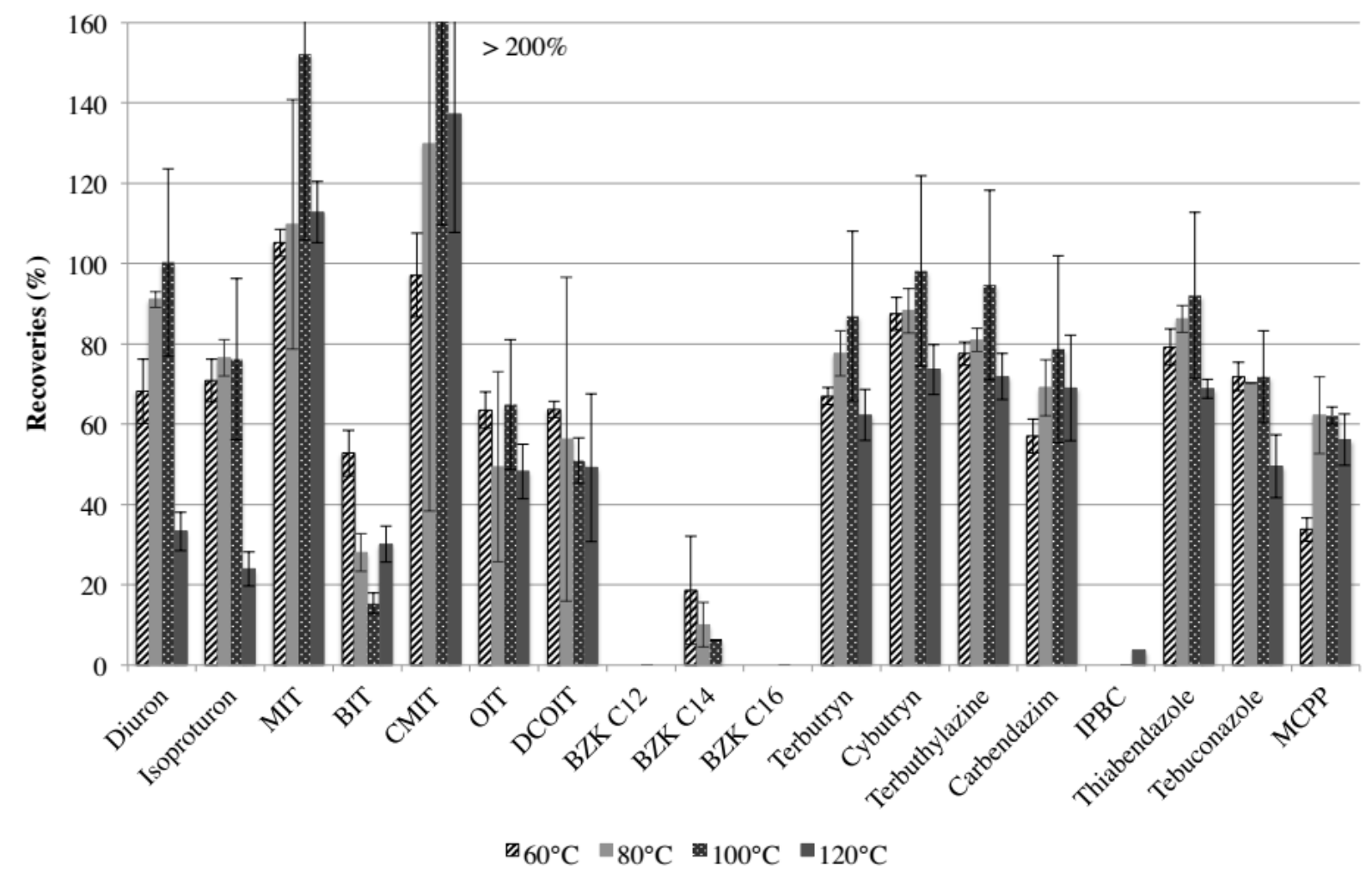

Fig. 2 MAE recovery rates at four different temperatures (mean \pm standard deviation)

Three replicates were extracted with a longer temperature plateau (15 min instead of $10 \mathrm{~min})$. For most of the biocides, recoveries were similar (less than $10 \%$ of difference) or higher with a shorter extraction time (ESM Fig. S8). Unfortunately, benzalkonium cations remained undetected in the extracts. The shortest temperature plateau of 10 min was thus kept.

Two different solvents were then tested: $\mathrm{MeOH} / \mathrm{DCM}(60 / 40 ; \mathrm{v} / \mathrm{v})$ and $\mathrm{MeOH}+0.1 \% \mathrm{HCOOH}(\mathrm{v} / \mathrm{v})$ in order to increase benzalkonium recoveries. Three replicates were extracted and recoveries are shown in ESM Fig. S9. Except for DCOIT, slightly lower recoveries were obtained with acidified MeOH (less than 20\% lower) and no difference was observed for benzalkonium compounds, which remained undetected. Similar RSDs were observed with MeOH/DCM (1 - 24\%) mixture or acidified MeOH (2 - 30\%). Thus, MeOH/DCM (60/40; v/v) was kept as extraction solvent.

Although some optimizations were performed, benzalkonium compounds and IPBC remained undetected in the extracts although filters had been spiked. This problem may come from the spiking step. Indeed, the filter was placed in a Petri dish (PTFE) in order to be spiked with $200 \mu \mathrm{L}$ of a solution containing all the targeted biocides $(50 \mu \mathrm{g} / \mathrm{L}$ in $\mathrm{MeOH})$. It was assumed that benzalkonium compounds and IPBC tend to adsorb on the Petri dish instead of the glass fiber filter, which could explain their very low recoveries in all extracts. Consequently, the method was not validated with spiked samples as explained in the materials and methods section, paragraph 1.5.4. 


\subsection{Method validation}

\subsubsection{UPLC-MS/MS}

Analytical blanks were analyzed in order to check the absence of any contamination during the analysis. Benzalkonium cations were detected in all analytical blanks. These compounds have long carbon chains and develop strong interactions with the column stationary phase. In order to remove this contamination, the column was rinsed with isopropanol, which has greater elution power for these compounds, for a couple of hours, but to no avail. Hence, only higher concentrations than those measured in blanks were considered. A few studies have reported this contamination, which may come, for example, from the mobile phase, but did not provide any solutions (Friedle et al. 2008; Hepperle et al. 2002; Slimani et al. 2017).

ESM Table S7 reports linearity ranges for all biocides. For isoproturon, BIT, OIT, DCOIT, terbutryn, cybutryn, terbuthylazine, carbendazim, IPBC, thiabendazole, tebuconazole and mecoprop, the linearity range was divided into two calibration curves: from the lowest detected concentration to $10 \mu \mathrm{g} / \mathrm{L}$ and from $10 \mu \mathrm{g} / \mathrm{L}$ to $150 \mu \mathrm{g} / \mathrm{L}$. For CMIT and benzalkonium compounds, the whole linearity range (up to 150 or $250 \mu \mathrm{g} / \mathrm{L}$ ) was validated. For diuron and MIT, smaller linearity ranges were observed (from the lowest detected concentration to $50 \mu \mathrm{g} / \mathrm{L}$ ).

Concerning instrumental repeatability, ESM Table S8 reports RSDs of the ratio between compound area and its corresponding IS area for the 18-targeted biocides. They ranged from 2\% (isoproturon) to $25 \%$ (mecoprop). Generally, RSDs were below $10 \%$, showing a good repeatability.

Concerning intermediate precision, RSDs were satisfactory $(<20 \%)$ for the lowest concentration of the linearity range for several biocides (terbutryn, cybutryn, terbuthylazine, carbendazim, thiabendazole, and tebuconazole). This value was thus considered as the LOQ . For MIT and DCOIT, the targeted RSDs were higher than for the other compounds, $35 \%$ and $30 \%$ respectively. For CMIT and benzalkonium compounds (C12-C16), the targeted value was fixed at $25 \%$ as RSDs remained higher than $20 \%$ for the whole linearity range.

All instrumental $\mathrm{LOQ}_{\mathrm{i}}$ values are reported in ESM Table $\mathrm{S} 9 . \mathrm{LOQ}_{\mathrm{i}}$ were $0.05 \mu \mathrm{g} / \mathrm{L}$ for isoproturon, terbutryn, cybutryn, terbuthylazine, carbendazim, thiabendazole and tebuconazole, and were hence equal to $\mathrm{LOD}_{\mathrm{i}}$; between 0.25 and $0.75 \mu \mathrm{g} / \mathrm{L}$ for diuron, MIT, BIT, OIT and DCOIT; $1 \mu \mathrm{g} / \mathrm{L}$ for IPBC and mecoprop; $2.5 \mu \mathrm{g} / \mathrm{L}$ for CMIT and benzalkonium compounds.

\subsubsection{SPE recoveries}

First, extraction blanks were analyzed: $100 \mathrm{~mL}, 200 \mathrm{~mL}$ and $500 \mathrm{~mL}$ of UP water were loaded following the SPE protocol described in ESM Table S2. No contamination was observed in blanks, except for benzalkonium compounds but this contamination did not exceed that observed in analytical blanks.

Mean SPE recoveries and the corresponding RSDs are presented in Table 2 for each matrix. Globally, good recoveries $(>70 \%)$ and low variation $(<25 \%)$ were observed. However, low recoveries were obtained for benzalkonium compounds: lower than $58 \%$ in surface water and WWTP influents/effluents, and than $34 \%$ in stormwater and CSOs. Also, significant variability was observed, as RSDs were up to $58 \%$ in CSOs for BZK C12. Therefore, only one significant digit was considered for benzalkonium compounds, which is enough to observe differences between matrices and to study the distribution between dissolved and particulate fractions. MIT recoveries ranged from $10 \%$ to $26 \%$. The lowest value was obtained in surface waters with a variability of $45 \%$, because of a higher volume load.

Matrix effects were observed as recoveries varied from one matrix to another. For instance, OIT recoveries were close to $100 \%$ in surface waters and WWTP effluents, but were lower $(76 \%-79 \%)$ in wastewater, stormwater and CSOs. Wick et al. (2010) also observed such a result for OIT. For some compounds (isoproturon, DCOIT, terbutryn, terbuthylazine, IPBC, tebuconazole and mecoprop), the signal may be exacerbated, leading to recoveries higher than 100\% (Chen et al. 2012). 
Table 2 SPE recoveries and RSDs for all the matrices

\begin{tabular}{|c|c|c|c|c|c|c|c|c|c|c|}
\hline \multirow[b]{2}{*}{ Biocides } & \multicolumn{2}{|c|}{$\begin{array}{c}\text { Surface } \\
\text { waters/rainwater }\end{array}$} & \multicolumn{2}{|c|}{$\begin{array}{c}\text { WWTP } \\
\text { effluents }\end{array}$} & \multicolumn{2}{|c|}{$\begin{array}{l}\text { WWTP } \\
\text { influents }\end{array}$} & \multicolumn{2}{|c|}{ Stormwater } & \multicolumn{2}{|c|}{ CSOs } \\
\hline & $\begin{array}{c}\text { SPE } \\
\text { recovery } \\
(\%)\end{array}$ & $\begin{array}{c}\text { RSD } \\
(\%)\end{array}$ & $\begin{array}{c}\text { SPE } \\
\text { recovery } \\
(\%)\end{array}$ & $\begin{array}{c}\text { RSD } \\
(\%)\end{array}$ & $\begin{array}{c}\text { SPE } \\
\text { recovery } \\
(\%)\end{array}$ & $\begin{array}{c}\text { RSD } \\
(\%)\end{array}$ & $\begin{array}{c}\text { SPE } \\
\text { recovery } \\
(\%)\end{array}$ & $\begin{array}{c}\text { RSD } \\
(\%)\end{array}$ & $\begin{array}{c}\text { SPE } \\
\text { recovery } \\
(\%)\end{array}$ & $\begin{array}{c}\text { RSD } \\
(\%)\end{array}$ \\
\hline Diuron & 75 & 8 & 100 & 15 & 82 & 33 & 70 & 28 & 79 & 10 \\
\hline Isoproturon & 91 & 13 & 118 & 18 & 113 & 26 & 122 & 10 & 89 & 15 \\
\hline MIT & 10 & 45 & 15 & 17 & 20 & 67 & 24 & 62 & 26 & 39 \\
\hline BIT & 73 & 21 & 87 & 18 & 150 & 44 & 101 & 23 & 74 & 15 \\
\hline CMIT & 62 & 42 & 80 & 28 & 46 & 37 & 52 & 17 & 66 & 31 \\
\hline OIT & 97 & 18 & 102 & 11 & 79 & 30 & 78 & 13 & 76 & 17 \\
\hline DCOIT & 224 & 31 & 234 & 25 & 128 & 66 & 48 & 36 & 184 & 35 \\
\hline BZK C12 & 30 & 51 & 24 & 55 & 34 & 33 & 24 & 58 & 34 & 42 \\
\hline BZK C14 & 32 & 46 & 27 & 22 & 55 & 50 & 20 & 48 & 30 & 41 \\
\hline BZK C16 & 42 & 34 & 58 & 6 & 58 & 55 & 5 & 31 & 7 & 32 \\
\hline Terbutryn & 80 & 11 & 110 & 22 & 98 & 38 & 76 & 26 & 79 & 11 \\
\hline Cybutryn & 72 & 13 & 94 & 17 & 81 & 33 & 64 & 19 & 74 & 18 \\
\hline Terbuthylazine & 89 & 23 & 111 & 27 & 97 & 46 & 77 & 33 & 75 & 10 \\
\hline Carbendazim & 59 & 14 & 80 & 38 & 82 & 37 & 86 & 9 & 70 & 17 \\
\hline IPBC & 82 & 15 & 116 & 18 & 100 & 40 & 94 & 42 & 98 & 16 \\
\hline Thiabendazole & 67 & 10 & 92 & 22 & 87 & 31 & 81 & 18 & 72 & 22 \\
\hline Tebuconazole & 129 & 42 & 136 & 19 & 122 & 34 & 89 & 25 & 90 & 18 \\
\hline Mecoprop & 98 & 28 & 123 & 21 & 110 & 24 & 88 & 13 & 108 & 24 \\
\hline
\end{tabular}

\subsubsection{MAE recoveries}

For each extraction, the absence of contamination was verified by an extraction blank ( $20 \mathrm{~mL}$ of extraction solvent). Again, contamination by benzalkonium compounds was observed but did not exceed that observed in analytical blanks. Only ten biocides among the 18 targeted were quantified in the six samples of wastewater (Fig. 3). Most of them showed good recoveries (> 75\%) in the first two fractions (F1 + F2) and RSDs were below $20 \%$. Lower recoveries (equal to 50\%) and higher variability (35\%) were observed for terbutryn and tebuconazole. For these two compounds, concentrations in real samples were corrected by these recoveries. For the others, concentrations were not corrected by their recovery rates.

\subsubsection{Matrix effects}

Matrix effects were determined for the three IS and are reported in ESM Table S9. For the dissolved fraction, average matrix effects ranged from $-26 \%$ in wastewater to $-3 \%$ in surface waters for isoproturon-d6, from $-18 \%$ in wastewater to $+9 \%$ in both treated wastewater and surface waters for terbuthylazine-d5, and from $-33 \%$ in surface waters to $+36 \%$ in CSOs for mecoprop-d3. In MAE extracts, they ranged from $-8 \%$ in treated wastewater to $+21 \%$ in stormwater for isoproturon-d6, from $-4 \%$ in treated wastewater to $+16 \%$ in stormwater for terbuthylazine-d5, and from $-31 \%$ in treated wastewater to $+19 \%$ in stormwater for mecoprop-d3.

\subsubsection{Limits of detection and quantification}

LOD and LOQ are provided in ESM (Table S10 and Table S11, respectively). In the dissolved fraction, LOQ range from $0.08 \mathrm{ng} / \mathrm{L}$ to $189 \mathrm{ng} / \mathrm{L}$ depending on the compound and the matrix. $\mathrm{LOD}_{\mathrm{D}}$ and $\mathrm{LOQ}_{\mathrm{D}}$ of diuron, isoproturon, OIT, DCOIT, terbutryn, cybutryn, terbuthylazine, carbendazim, thiabendazole and tebuconazole are below $1 \mathrm{ng} / \mathrm{L}$; LOD $\mathrm{D}_{\mathrm{D}}$ and LOQD of MIT, BIT, CMIT, IPBC and mecoprop are between 1 and $50 \mathrm{ng} / \mathrm{L}$, and LOD and $\mathrm{LOQ}_{\mathrm{D}}$ of benzalkonium compounds can be higher than $50 \mathrm{ng} / \mathrm{L}$ because of higher instrumental limits and lower recoveries. However, all LOQ remain below PNEC values in surface waters and are thus suitable for environmental analysis. In the literature, $\mathrm{LOQ}_{\mathrm{D}}$ vary from one study to another but most of the studies can quantify biocides at concentrations in the range of ng/L or lower (Chen et al. 2012; Moschet et al. 2013; Singer et al. 2010; Van de Voorde et al. 2012; Wieck et al. 2018). In this study, LOQD of BIT, OIT and DCOIT are lower than those 
previously reported by Rafoth et al. (2007), Singer et al. (2010), Wick et al. (2010), and Wieck et al. (2018). For CMIT, Singer et al. (Singer et al. 2010) obtained LOQD of the same order of magnitude (35-40 ng/L) and Wieck et al. (2018) slightly lower (10 ng/L). With regard to benzalkonium compounds, they were quantified by Van de Voorde et al. (2012) at lower concentrations (between 0.07 and $0.09 \mathrm{ng} / \mathrm{L}$ ). This latter study focused on the analysis of only five quaternary ammonium compounds, whereas the present study describes a multi-residue analysis and extraction issues were encountered.

In the particulate fraction, $\mathrm{LOD}_{\mathrm{P}}$ and $\mathrm{LOQ}_{\mathrm{P}}$ values rely on the mass of extracted particles, which varies from one sample to another: from 10 to $51 \mathrm{mg}$ in rainwater, from 8.5 to $103 \mathrm{mg}$ in surface waters, from 4.3 to $11 \mathrm{mg}$ in WWTP effluents, from 54 to $84 \mathrm{mg}$ in WWTP influents, from 27 to $130 \mathrm{mg}$ in CSOs, and from 28 to $84 \mathrm{mg}$ in stormwater. Consequently, LODP and $\mathrm{LOQ}_{\mathrm{P}}$ values can also vary from one order of magnitude to another, especially in surface waters. Minimum and maximum values are reported in ESM Table S11. For most of the biocides, LOQP values are in the range of few ng/g.dw. As in the dissolved fraction, limits are higher for benzalkonium compounds and isothiazolinones due to higher instrumental limits.

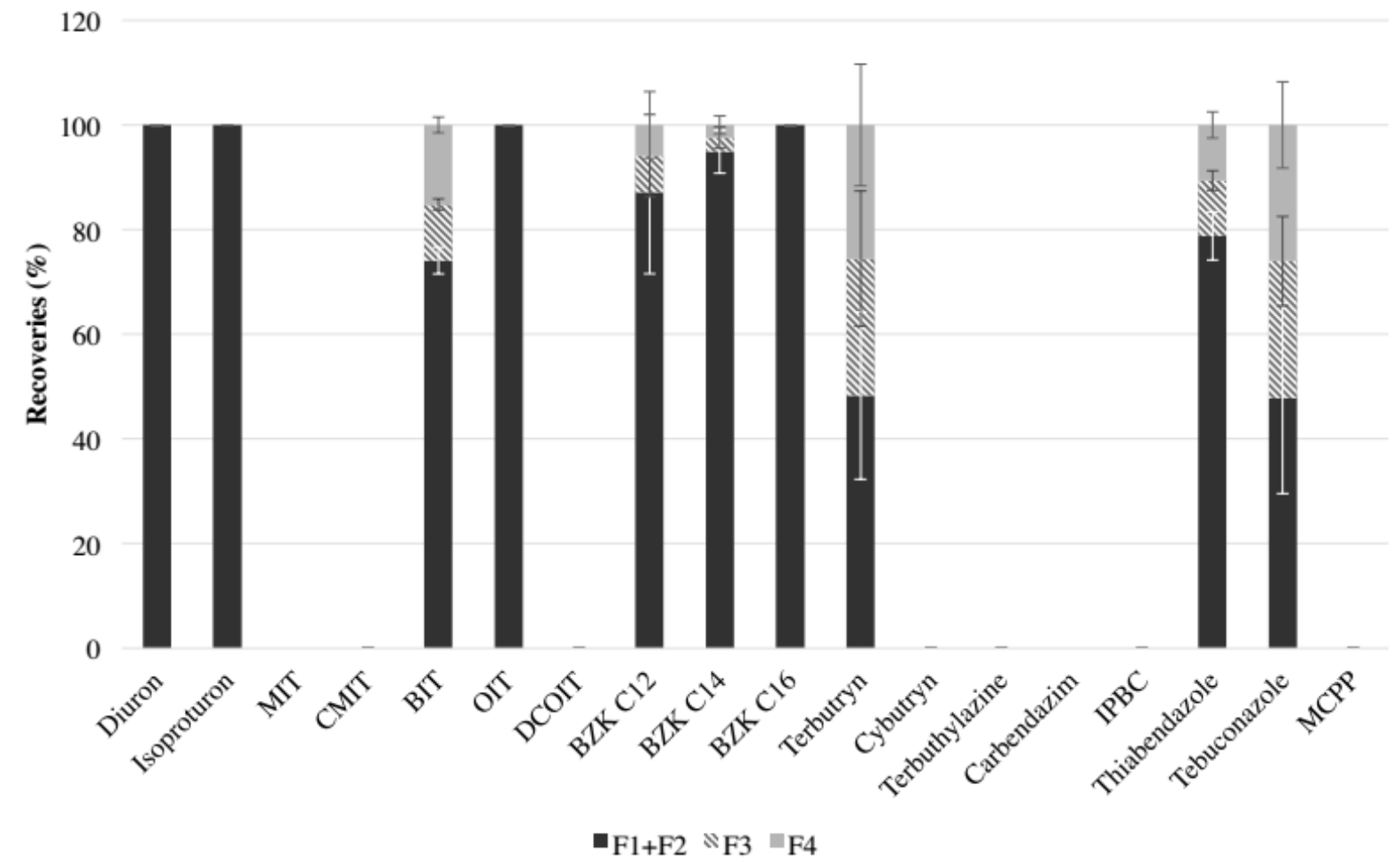

Fig. 3 Amount of biocides collected in each particulate fraction of the six wastewater samples $(F 1+F 2, F 3, F 4)$ compared to the total amount collected $(\mathrm{F} 1+\mathrm{F} 2+\mathrm{F} 3+\mathrm{F} 4)$

\section{Application to environmental samples}

The analytical method was successfully applied to many urban and surface waters. Three sampling campaigns were conducted for each sampling site. The measured concentrations in both dissolved (D ng/L) and particulate ( $\mathrm{P}^{*} \mathrm{ng} / \mathrm{g} . \mathrm{dw}$ ) fractions are reported in Table 3. Results are discussed in terms of total concentrations (sum of dissolved (D) and particulate concentrations ( $\mathrm{P}, \mathrm{P}=\mathrm{P}^{*} \times \mathrm{C}_{\mathrm{ss}}$ where $\mathrm{C}_{\mathrm{SS}}$ is the $\mathrm{SS}$ concentration in $\left.\mathrm{g} / \mathrm{L}\right)$ ).

In rainwater, biocides were frequently detected and quantified. Most of them were measured with a total concentration below $5 \mathrm{ng} / \mathrm{L}$ (see ESM Table S12). However, some biocides were quantified at higher concentrations: terbuthylazine, IPBC and tebuconazole were once measured at 38, 13 and $10 \mathrm{ng} / \mathrm{L}$ respectively and all samples were contaminated by MIT (39-106 ng/L), CMIT (5.6-57 ng/L), BZK C12 (38-149 ng/L), and BZK C14 (19-68 ng/L). Few data are available in the literature concerning biocide concentrations in urban rainwater. A few studies (Bressy et al. 2012; Potter and Coffin 2017; Scheyer et al. 2007; Zgheib et al. 2012) have 
reported dissolved concentrations of diuron, isoproturon, mecoprop and tebuconazole (because of their use as pesticides) much higher than in this work, up to $1.7 \mu \mathrm{g} / \mathrm{L}$ for diuron. A more recent study measured similar dissolved concentrations of terbutryn (0.3-10 ng/L) in Singapore (Zhang et al. 2018).

Three levels of total concentration were observed in WWTP influents: concentrations of MIT, BIT and benzalkonium compounds were significantly higher than $100 \mathrm{ng} / \mathrm{L}$, concentrations of terbutryn, carbendazim, thiabendazole and mecoprop were between 10 and $100 \mathrm{ng} / \mathrm{L}$, and concentrations of isoproturon, CMIT, OIT, DCOIT, cybutryn and IPBC were below $10 \mathrm{ng} / \mathrm{L}$. Concentrations in effluents were of the same order of magnitude, which highlights the limited effects of such treatments to remove those micropollutants. Only MIT and BIT concentrations were significantly lower in effluents compared to influents.

In CSOs, BZK C12 and C14 were measured up to $6 \mu \mathrm{g} / \mathrm{L}$, diuron up to $0.9 \mu \mathrm{g} / \mathrm{L}$ and BZK C16 up to $0.7 \mu \mathrm{g} / \mathrm{L}$. Only IPBC was never quantified in both fractions. Concentrations can vary from one order of magnitude to another for MIT, BIT, terbuthylazine, thiabendazole and mecoprop. This could be explained by the variability of storm events (rain intensity, runoff quantity, etc.). In stormwater, BZK C12 was measured with the highest concentrations, up to $20 \mu \mathrm{g} / \mathrm{L}$. For most of the biocides, concentrations were between 10 and $100 \mathrm{ng} / \mathrm{L}$. Concentrations above $100 \mathrm{ng} / \mathrm{L}$ were systematically observed for BZK C14, BZK C16 mecoprop and occasionally for MIT and BIT. Only a few studies have reported some biocide concentrations in stormwater or CSOs (Birch et al. 2011; Gasperi et al. 2008, 2013; Launay et al. 2016; Van de Voorde et al. 2012; Wicke et al. 2015) and only Launay et al. (2016) and Van de Voorde et al. (2012) considered both dissolved and particulate fractions. Significant inter- and intra-study variability was observed, as concentrations depend on the study site, the impervious surface area, or rain intensity. Globally, the concentrations are in agreement with those measured in the present study.

In surface waters, total concentrations were generally below $10 \mathrm{ng} / \mathrm{L}$, but higher concentrations were measured during the first sampling campaign for diuron, BZK C12, terbuthylazine, tebuconazole, and mecoprop. These peaks in concentration might be due to weather and hydrological conditions, as this campaign was conducted during a rainy and flood period. It was also conducted in June, i.e. during a period of pesticide application. Biocides might have leached from soils and building materials. Measured dissolved concentrations occasionally exceeded PNEC values (reported in ESM Table S1) for BZK C12 and diuron. Concentrations of terbuthylazine were of the same order of magnitude as its PNEC. These biocides might therefore represent a risk for aquatic organisms.

Generally, most of the biocides were measured in both dissolved and particulate fractions, but they remain mostly dissolved. Only IPBC was rarely quantified in the dissolved fraction while being frequently measured in the particles. The partition between the particulate and the dissolved fractions is reported in ESM Table S13. The particulate proportion were lower than $20 \%$ in most of the samples but they were variable and some compounds could occasionally be most present in particles. For example, particulate proportions of MIT, which is the most hydrophilic compound in this study, varied from $0 \%$ in WWTP influents/effluents to $100 \%$ in surface waters or CSOs. The particulate proportions of terbutryn, the biocide with the highest octanol/water-partitioning coefficient ( $\log$ Kow of 3.7$)$ in this study, were below $5 \%$ in most of the samples and never exceeded 48\%. Proportions of biocides in the particulate fraction depend on the matrix and do not seem to be related to the compound's hydrophobicity. For benzalkonium compounds in particular, their cationic character could also play a role in the sorption mechanisms, as they remained mostly in the dissolved fraction (See ESM Table S13). These results highlight the presence of biocides in particles and thus the need to analyze both dissolved and particulate fractions of water samples in order to assess the transfer of biocides to sediments. 
Table 3 Concentrations of biocides in dissolved $(\mathrm{D}$, in $\mathrm{ng} / \mathrm{L})$ and particulate $\left(P^{*}\right.$, in $\left.n g / g . d w\right)$ fractions of different urban waters and surface waters

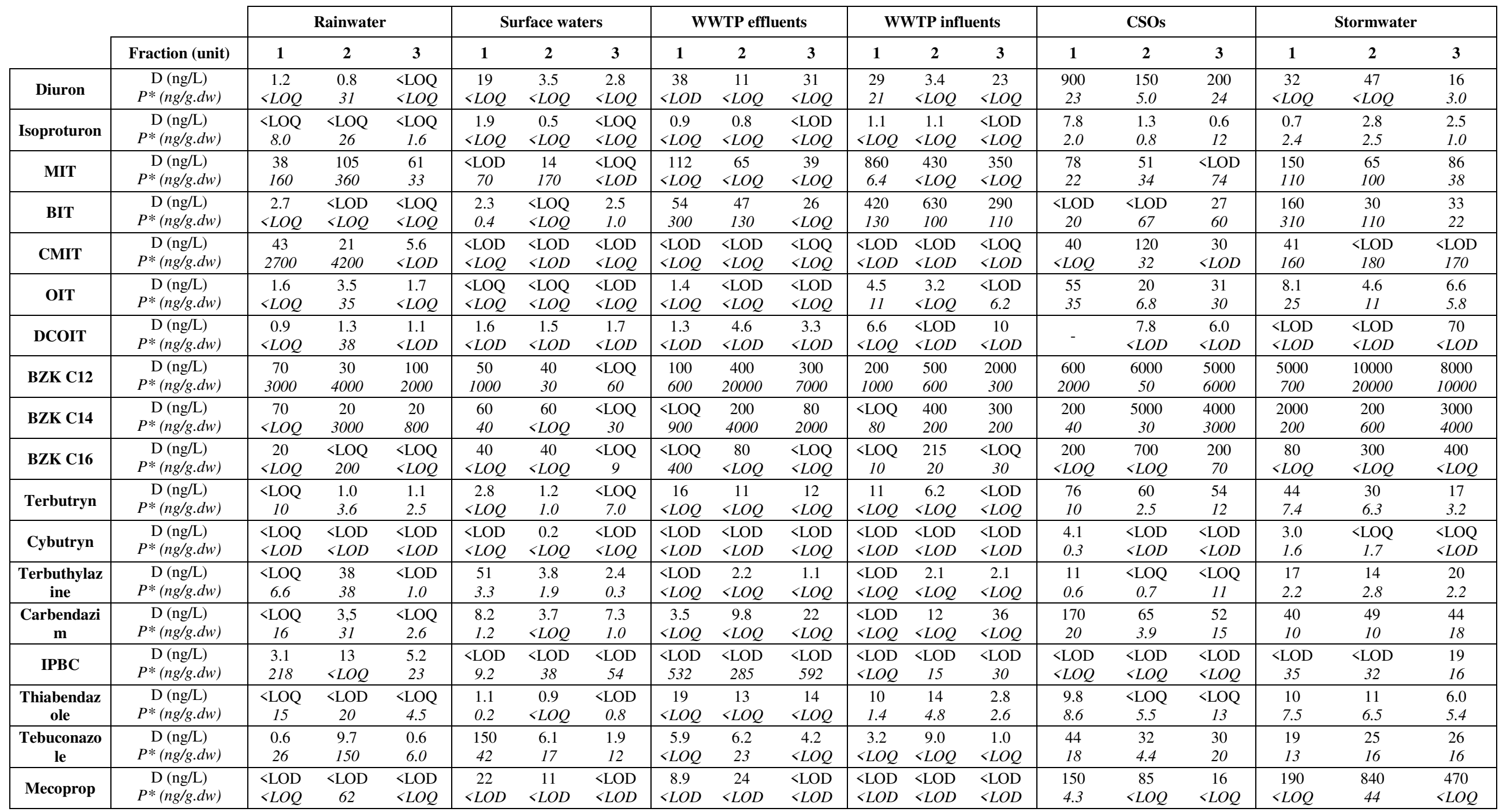




\section{Conclusion}

A fast, sensitive and accurate method was developed to analyze by HPLC-MS/MS 18 biocides employed, among other things, in building materials in both dissolved and particulate fractions of many water samples. The dissolved fraction was extracted by SPE, which provides good recoveries for most of the biocides (> 70\%), except for MIT $(<25 \%)$ and benzalkonium compounds (often lower than 35\%), because of their respectively strong hydrophilic and hydrophobic properties. The method developed allows the particulate fraction of diverse water samples to be extracted by MAE, which has rarely been done in previous studies. Thanks to this procedure, biocides can be quantified in samples at trace level, in the range of $\mathrm{ng} / \mathrm{L}$ in the dissolved fraction and in the range of $\mathrm{ng} / \mathrm{g} . \mathrm{dw}$ in the particulate fraction for most of the biocides and matrices. This method is thus suitable for biocide monitoring in urban and surface waters. It was successfully applied to rainwater, surface waters, WWTP influents and effluents, CSOs, and stormwater. The results highlighted the presence of biocides in both fractions and the relevance of measuring these substances in the particulate fraction. In rainwater, biocides are less frequently quantified. In urban waters, concentrations of biocides ranged from few ng/L to hundreds of ng/L depending on the compound and the sampling campaign. Finally, in surface waters, most of the biocides were measured at less than $10 \mathrm{ng} / \mathrm{L}$, but peaks in concentration were observed after rain events, exceeding PNEC levels. These first results point to a significant transfer of biocides from the urban environment to surface waters via stormwater and treated wastewater discharges, and a potential risk to aquatic organisms.

\section{Author contributions}

The manuscript was written through contributions of all authors. All authors have given approval to the final version of the manuscript.

\section{Notes}

The authors declare no competing financial interest.

\section{Acknowledgment}

The authors gratefully acknowledge the Central Laboratory of the Police Prefecture of Paris (LCPP) for the funding of this work. The study has been performed within the framework of the OPUR research program funded by the Seine-Normandy Water Agency, the City of Paris, the greater Paris sanitation authority (SIAAP), the Hauts-deSeine Departmental Council, the Seine Saint-Denis Departmental Council and the Val-de-Marne Departmental Council. The authors also thank the Brigade Fluviale de la Préfecture de Police (Major Bizeray) and the Brigade Fluviale de la Gendarmerie Nationale des Yvelines (Major Duquesnois), the SIAAP (in particular Vincent Rocher, Romain Mailler and Céline Briand) and the City of Paris (in particular Pascale Neveu and Frédéric Béthouart) for their assistance during sampling campaigns. 


\section{Bibliography}

Andrade, T. S., Henriques, J. F., Almeida, A. R., Machado, A. L., Koba, O., Giang, P. T., Soares, A. M.V.M., \& Domingues, I. (2016). Carbendazim Exposure Induces Developmental, Biochemical and Behavioural Disturbance in Zebrafish Embryos. Aquatic Toxicology, 170, 390-99. https://doi.org/10.1016/j.aquatox.2015.11.017.

Bester, K., \& Lamani, X. (2010). Determination of biocides as well as some biocide metabolites from facade runoff waters by solid phase extraction and high performance liquid chromatographic separation and tandem mass spectrometry detection. Journal of Chromatography A, 1217(32), 5204-5214. https://doi.org/10.1016/j.chroma.2010.06.020

Bester, K., Scholes, L., Wahlberg, C., \& McArdell, C. S. (2008). Sources and Mass Flows of Xenobiotics in Urban Water Cycles_-an Overview on Current Knowledge and Data Gaps. Water Air Soil Pollut, 17.

Birch, H., Mikkelsen, P. S., Jensen, J. K., \& Lützhøft, H.-C. H. (2011). Micropollutants in stormwater runoff and combined sewer overflow in the Copenhagen area, Denmark. Water Science \& Technology, 64(2), 485-493. https://doi.org/10.2166/wst.2011.687

Bollmann, U. E., Minelgaite, G., Schlüsener, M., Ternes, T., Vollertsen, J., \& Bester, K. (2016). Leaching of Terbutryn and Its Photodegradation Products from Artificial Walls under Natural Weather Conditions. Environmental Science \& Technology, 50(8), 4289-4295. https://doi.org/10.1021/acs.est.5b05825

Bollmann, U. E., Vollertsen, J., Carmeliet, J., \& Bester, K. (2014a). Dynamics of biocide emissions from buildings in a suburban stormwater catchment - Concentrations, mass loads and emission processes. Water Research, 56, 66-76. https://doi.org/10.1016/j.watres.2014.02.033

Bollmann, U. E., Tang, C., Eriksson, E., Jönsson, K., Vollertsen, J., \& Bester, K. (2014b). Biocides in urban wastewater treatment plant influent at dry and wet weather: Concentrations, mass flows and possible sources. Water Research, 60, 64-74. https://doi.org/10.1016/j.watres.2014.04.014

Bollmann, U. E., Minelgaite, G., Schlüsener, M., Ternes, T. A., Vollertsen, J., \& Bester, K. (2017). Photodegradation of octylisothiazolinone and semi-field emissions from facade coatings. Scientific Reports, 7 , 41501-1-9. https://doi.org/10.1038/srep41501

Bressy, A., Gromaire, M.-C., Lorgeoux, C., Saad, M., Leroy, F., \& Chebbo, G. (2012). Towards the determination of an optimal scale for stormwater quality management: Micropollutants in a small residential catchment. Water Research, 46(20), 6799-6810. https://doi.org/10.1016/j.watres.2011.12.017

Burkhardt, M., Junghans, M., Zuleeg, S., Boller, M., Schoknecht, U., Lamani, X., Bester, K., Vonbank, R., \& Simmler, S. (2009). Biozide in Gebäudefassaden - ökotoxikologische Effekte, Auswaschung und Belastungsabschätzung für Gewässer. Umweltwissenschaften und Schadstoff-Forschung, 21(1), 36-47. https://doi.org/10.1007/s12302-008-0033-1.

Burkhardt, M., Zuleeg, S., Vonbank, R., Bester, K., Carmeliet, J., Boller, M., \& Wangler, T. (2012). Leaching of Biocides from Façades under Natural Weather Conditions. Environmental Science \& Technology, 46(10), 54975503. https://doi.org/10.1021/es2040009

Burkhardt, M., Zuleeg, S., Vonbank, R., Schmid, P., Hean, S., Lamani, X., et al. (2011). Leaching of additives from construction materials to urban storm water runoff. Water Science \& Technology, 63(9), 1974-1982. https://doi.org/10.2166/wst.2011.128

Chen, Z.-F., Ying, G.-G., Lai, H.-J., Chen, F., Su, H.-C., Liu, Y.-S., et al. (2012). Determination of biocides in different environmental matrices by use of ultra-high-performance liquid chromatography-tandem mass spectrometry. Analytical and Bioanalytical Chemistry, 404(10), 3175-3188. https://doi.org/10.1007/s00216-0126444-2

Chitescu, C. L., Oosterink, E., de Jong, J., \& Stolker, A. A. M. L. (2012). Ultrasonic or accelerated solvent extraction followed by U-HPLC-high mass accuracy MS for screening of pharmaceuticals and fungicides in soil and plant samples. Talanta, 88, 653-662.

Cotton, J., Leroux, F., Broudin, S., Poirel, M., Corman, B., Junot, C., \& Ducruix, C. (2016). Development and validation of a multiresidue method for the analysis of more than 500 pesticides and drugs in water based on online and liquid chromatography coupled to high resolution mass spectrometry. Water Research, 104, 20-27. https://doi.org/10.1016/j.watres.2016.07.075 
Dulio, V., von der Ohe, P. C., Botta, F., Ipolyi, I., Ruedel, H., \& Slobodnik, J. (2015). The NORMAN Network Special view on biocides as emerging substances, présentation Workshop NORMAN, 25-26 juin 2015, Berlin, Allemagne. Berlin. http://www.norman-network.net/?q=node/230

Friedle, A., Thumulla, J., \& Snepvangers, K. (2008). Quaternary ammonium compounds (QUAT) in house dust. Indoor Air, 4, 17-22.

Gasperi, J., Garnaud, S., Rocher, V., \& Moilleron, R. (2008). Priority pollutants in wastewater and combined sewer overflow. Science of The Total Environment, 407(1), 263-272. https://doi.org/10.1016/j.scitotenv.2008.08.015

Gasperi, J., Sebastian, C., Ruban, V., Delamain, M., Percot, S., Wiest, L., et al. (2013). Micropollutants in urban stormwater: occurrence, concentrations, and atmospheric contributions for a wide range of contaminants in three French catchments. Environmental Science and Pollution Research, 21(8), 5267-5281. https://doi.org/10.1007/s11356-013-2396-0

Geara-Matta, D. (2012). Flux et sources des parabènes, du triclosan et du triclocarban en milieux urbains denses: comparaison entre Paris et Beyrouth. Thèse de doctorat (Sciences de l'Univers et Environnement). Université Paris-Est, $178 \mathrm{p}$.

Geissen, V., Mol, H., Klumpp, E., Umlauf, G., Nadal, M., van der Ploeg, M., et al. (2015). Emerging pollutants in the environment: A challenge for water resource management. International Soil and Water Conservation Research, 3(1), 57-65. https://doi.org/10.1016/j.iswcr.2015.03.002

Hepperle, J., Schüle, E., Kolberg, D., \& Scherbaum, E. (2002). Determination of quaternary ammonium compound residues in fruits and vegetables by QuEChERS following LC-MS/MS analysis. 5 . https://pdfs.semanticscholar.org/9f07/d9f1ae9b695391792d05fb5027df23225585.pdf

Hildebrandt, A., Lacorte, S., \& Barceló, D. (2007). Assessment of priority pesticides, degradation products, and pesticide adjuvants in groundwaters and top soils from agricultural areas of the Ebro river basin. Analytical and Bioanalytical Chemistry, 387, 1459-1468.

Huang, O., Zhang, J., Xiong, S., Peng, X., Wei, G., Liu, L., et al. (2018). Development of Ultrasound-Assisted Extraction of Commonly Used Azole Antifungals in Soils. Analytical Methods, 10(44), 5265-5272.

Jiang, J., Wu, S., Wang, Y., An, X., Cai, L., Zhao, X., \& Wu, C. (2015). Carbendazim Has the Potential to Induce Oxidative Stress, Apoptosis, Immunotoxicity and Endocrine Disruption during Zebrafish Larvae Development. Toxicology in Vitro, 29 (7), 1473-81. https://doi.org/10.1016/j.tiv.2015.06.003.

Juksu, K., Zhao, J.-L., Liu, Y.-S., Yao, L., Sarin, C., Sreesai, S., et al. (2019). Occurrence, fate and risk assessment of biocides in wastewater treatment plants and aquatic environments in Thailand. Science of The Total Environment, 690, 1110-1119.

Kalogridi, E.-C., Christophoridis, C., Bizani, E., Drimaropoulou, G., \& Fytianos, K. (2014). Part II: temporal and spatial distribution of multiclass pesticide residues in lake sediments of northern Greece: application of an optimized MAE-LC-MS/MS pretreatment and analytical method. Environmental Science and Pollution Research, 21(12), 7252-7262.

Launay, M. A., Dittmer, U., \& Steinmetz, H. (2016). Organic micropollutants discharged by combined sewer overflows - Characterisation of pollutant sources and stormwater-related processes. Water Research, 104, 82-92. https://doi.org/10.1016/j.watres.2016.07.068

Masiá, A., Vásquez, K., Campo, J., \& Picó, Y. (2015). Assessment of two extraction methods to determine pesticides in soils, sediments and sludges. Application to the Túria River Basin. Journal of Chromatography A, 1378, 19-31. https://doi.org/10.1016/j.chroma.2014.11.079

Merel, S., Benzing, S., Gleiser, C., Di Napoli-Davis, G., \& Zwiener, C. (2018). Occurrence and overlooked sources of the biocide carbendazim in wastewater and surface water. Environmental Pollution, $239,512-521$. https://doi.org/10.1016/j.envpol.2018.04.040

Miege, C., Dugay, J., \& Hennion, M. C. (2003). Optimization, validation and comparison of various extraction techniques for the trace determination of polycyclic aromatic hydrocarbons in sewage sludges by liquid chromatography coupled to diode-array and fluorescence detection. Journal of Chromatography A, 995(1-2), 8797.

Mohr, S., Schröder, H., Feibicke, M., Berghahn, R., Arp, W., \& Nicklisch, A. (2008). Long-term effects of the 
antifouling booster biocide Irgarol 1051 on periphyton, plankton and ecosystem function in freshwater pond mesocosms. Aquatic Toxicology, 90(2), 109-120. https://doi.org/10.1016/j.aquatox.2008.08.004

Mompelat, S., Fourmond, M.-P., Laurentie, M., Verdon, E., Hurtaud-Pessel, D., \& Abjean, J.-P. (2015). Validation of a liquid chromatography-high-resolution mass spectrometry method for the analysis of ceftiofur in poultry muscle, kidneys and plasma: A unique accuracy profile for each and every matrix. Journal of Chromatography A, 1407, 119-129. https://doi.org/10.1016/j.chroma.2015.06.043

Moschet, C., Piazzoli, A., Singer, H., \& Hollender, J. (2013). Alleviating the reference standard dilemma using systematic exact mass suspect screening approach with liquid chromatography-high resolution mass spectrometry. Analytical Chemistry, 85, 10312-10320.

Moschet, C., Wittmer, I., Simovic, J., Junghans, M., Piazzoli, A., Singer, H. P., et al. (2014). How a Complete Pesticide Screening Changes the Assessment of Surface Water Quality. Environmental Science \& Technology, 48(10), 5423-5432. https://doi.org/10.1021/es500371t

Östman, M., Lindberg, R. H., Fick, J., Björn, E., \& Tysklind, M. (2017). Screening of biocides, metals and antibiotics in Swedish sewage sludge and wastewater. Water research, 115, 318-328.

Paijens, C., Bressy, A., Frère, B., \& Moilleron, R. (2019). Prioritization of leached biocides from building materials towards aquatic environment monitoring (in French). Techniques Sciences Méthodes, 122019. https://doi.org/10.36904/tsm/201912197

Paijens, C., Bressy, A., Frère, B., \& Moilleron, R. (2020). Biocide emissions from building materials during wet weather: identification of substances, mechanism of release and transfer to the aquatic environment. Environmental Science and Pollution Research. https://doi.org/10.1007/s11356-019-06608-7

Potter, T. L., \& Coffin, A. W. (2017). Assessing pesticide wet deposition risk within a small agricultural watershed in the Southeastern Coastal Plain (USA). Science of The Total Environment, 580, 158-167.

Rafoth, A., Gabriel, S., Sacher, F., \& Brauch, H.-J. (2007). Analysis of isothiazolinones in environmental waters by gas chromatography-mass spectrometry. Journal of Chromatography A, 1164(1-2), 74-81. https://doi.org/10.1016/j.chroma.2007.07.040

Sánchez-Rodríguez, A., Sosa-Ferrera, Z., \& Santana-Rodríguez, J. J. (2011). Applicability of microwave-assisted extraction combined with LC-MS/MS in the evaluation of booster biocide levels in harbour sediments. Chemosphere, 82, 96-102.

Scheyer, A., Morville, S., Mirabel, P., \& Millet, M. (2007). Pesticides analysed in rainwater in Alsace region (Eastern France): Comparison between urban and rural sites. Atmospheric Environment, 41, 7241-7252.

Shah, J., Jan, M. R., Ara, B., \& Shehzad, F.-N. (2011). Quantification of triazine herbicides in soil by microwaveassisted extraction and high-performance liquid chromatography. Environmental Monitoring and Assessment, 178(111-119).

Singer, H. P., Jaus, S., Hanke, I., Lück, A., Hollender, J., \& Alder, A. C. (2010). Determination of biocides and pesticides by on-line solid phase extraction coupled with mass spectrometry and their behaviour in wastewater and surface water. Environmental Pollution, 158(10), 3054-3064. https://doi.org/10.1016/j.envpol.2010.06.013

Slimani, K., Féret, A., Pirotais, Y., Maris, P., Abjean, J.-P., \& Hurtaud-Pessel, D. (2017). Liquid chromatographytandem mass spectrometry multiresidue method for the analysis of quaternary ammonium compounds in cheese and milk products: Development and validation using the total error approach. Journal of Chromatography A, 1517, 86-96. https://doi.org/10.1016/j.chroma.2017.08.034

Stipičević, S., Galzina, N., Udiković-Kolić, N., Jurina, T., Mendaš, G., Dvoršćak, M., et al. (2015). Distribution of terbuthylazine and atrazine residues in crop-cultivated soil: The effect of herbicide application rate on herbicide persistence. Geoderma, 259-260, 300-309.

Uhl, M., Gans, O., Grillitsch, B., Fürhacker, M., \& Kreuzinger, N. (2005). Grundlagen Zur Risikoabschätzung Für Quaternäre Ammoniumverbindungen, 157 p. http://www.academia.edu/download/40282155/Grundlagen_zur_Risikoabschtzung_fr_quate20151122-11272eisz97.pdf.

Van de Voorde, A., Lorgeoux, C., Gromaire, M.-C., \& Chebbo, G. (2012). Analysis of quaternary ammonium compounds in urban stormwater samples. Environmental Pollution, 164, 150-157. 
https://doi.org/10.1016/j.envpol.2012.01.037

Vermeirssen, E. L. M., Campiche, S., Dietschweiler, C., Werner, I., \& Burkhardt, M. (2018). Ecotoxicological Assessment of Immersion Samples from Facade Render Containing Free or Encapsulated Biocides: Ecotoxicity of leachates from facade renders with biocides. Environmental Toxicology and Chemistry, 37(8), 2246-2256. https://doi.org/10.1002/etc.4176

Vial, J., Le Mapihan, K., \& Jardy, A. (2003). What is the best means of estimating the detection and quantification limits of a chromatographic method? Chromatographia, 57(1), S303-S306.

Wick, A., Fink, G., \& Ternes, T. A. (2010). Comparison of electrospray ionization and atmospheric pressure chemical ionization for multi-residue analysis of biocides, UV-filters and benzothiazoles in aqueous matrices and activated sludge by liquid chromatography-tandem mass spectrometry. Journal of Chromatography A, 1217(14), 2088-2103. https://doi.org/10.1016/j.chroma.2010.01.079

Wicke, D., Matzinger, A., \& Rouault, P. (2015). Relevanz organischer Spurenstoffe im Regenwasserabfluss Berlins. Kompetenzzentrum Wasser Berlin, 99 p. https://www.kompetenz-wasser.de/wpcontent/uploads/2017/11/abschlussbericht_ogre_final_rev2.pdf

Wieck, S., Olsson, O., \& Kümmerer, K. (2018). Not only biocidal products: Washing and cleaning agents and personal care products can act as further sources of biocidal active substances in wastewater. Environment International, 115, 247-256. https://doi.org/10.1016/j.envint.2018.03.040

Wieck, S., Olsson, O., \& Kümmerer, K. (2016). Possible underestimations of risks for the environment due to unregulated emissions of biocides from households to wastewater. Environment international, 94, 695-705.

Zgheib, S., Moilleron, R., \& Chebbo, G. (2012). Priority pollutants in urban stormwater: Part 1 - Case of separate storm sewers. Water Research, 46(20), 6683-6692. https://doi.org/10.1016/j.watres.2011.12.012

Zhang, H., Watts, S., Philix, M. C., Snyder, S. A., \& Ong, C. N. (2018). Occurrence and distribution of pesticides in precipitation as revealed by targeted screening through GC-MS/MS. Chemosphere, 211, 210-217. 


\title{
Electronic Supplementary material
}

\section{Determination of 18 biocides in both the dissolved and particulate fractions of urban and surface waters by HPLC-MS/MS}

\author{
Claudia Paijens $^{1,2}$, Bertrand Frère ${ }^{2}$, Emilie Caupos $^{l}$, Régis Moilleron ${ }^{1}$, and Adèle Bressy ${ }^{1, *}$ \\ ${ }^{1}$ Leesu, Ecole des Ponts, Univ Paris Est Creteil, Marne-la-Vallee, France \\ ${ }^{2}$ Laboratoire Central de la Préfecture de Police, Paris, France \\ *corresponding author: adele.bressy@enpc.fr
}

Table S1 Information on the 18-targeted biocides

\begin{tabular}{|c|c|c|c|c|c|c|c|}
\hline Biocide & $\begin{array}{l}\text { Abbre- } \\
\text { viation }\end{array}$ & $\begin{array}{c}\text { CAS } \\
\text { number }\end{array}$ & Formula & $\begin{array}{c}\text { MW } \\
(\mathrm{g} / \mathrm{mol})\end{array}$ & Log Kow & pKa & $\begin{array}{l}\text { PNEC } \\
(\mu \mathrm{g} / \mathrm{L})\end{array}$ \\
\hline Diuron & & $330-54-1$ & $\mathrm{C}_{9} \mathrm{H}_{10} \mathrm{Cl}_{2} \mathrm{~N}_{2} \mathrm{O}$ & 233,1 & 2,85 & & 0,02 \\
\hline Isoproturon & & $34123-59-6$ & $\mathrm{C}_{12} \mathrm{H}_{18} \mathrm{~N}_{2} \mathrm{O}$ & 206,3 & 2,5 & & 0,021 \\
\hline Methylisothiazolinone & MIT & $2682-20-4$ & $\mathrm{C}_{4} \mathrm{H}_{5} \mathrm{NOS}$ & 115,2 & $-0,49$ & & 3,9 \\
\hline Benzisothiazolinone & BIT & $2634-33-5$ & $\mathrm{C}_{7} \mathrm{H}_{5} \mathrm{NOS}$ & 151,2 & 0,64 & & \\
\hline $\begin{array}{c}\text { Chloro- } \\
\text { methylisothiazolinone } \\
\end{array}$ & CMIT & $26172-55-4$ & $\mathrm{C}_{4} \mathrm{H}_{4} \mathrm{ClNOS}$ & 149,6 & 0,4 & & 0,049 \\
\hline Octylisothiazolinone & OIT & $26530-20-1$ & $\mathrm{C}_{11} \mathrm{H}_{19} \mathrm{NOS}$ & 213,3 & 2,45 & & 0,013 \\
\hline $\begin{array}{c}\text { Dichloro- } \\
\text { octylisothiazolinone }\end{array}$ & DCOIT & $64359-81-5$ & $\mathrm{C}_{11} \mathrm{H}_{17} \mathrm{Cl}_{2} \mathrm{NOS}$ & 282,2 & 3,59 & & 0,008 \\
\hline $\begin{array}{c}\text { Benzyldimethyldodecyl } \\
\text { ammonium chloride }\end{array}$ & BZK C12 & $139-07-1$ & $\mathrm{C}_{21} \mathrm{H}_{38} \mathrm{ClN}$ & 304,5 & 1,7 & & 0,04 \\
\hline $\begin{array}{l}\text { Benzyldimethyltetrade } \\
\text { cyl ammonium chloride }\end{array}$ & BZK C14 & $139-08-2$ & $\mathrm{C}_{23} \mathrm{H}_{42} \mathrm{ClN}$ & 346,6 & 2,5 & & \\
\hline $\begin{array}{l}\text { Benzyldimethylhexadec } \\
\text { yl ammonium chloride }\end{array}$ & BZK C16 & $122-18-9$ & $\mathrm{C}_{25} \mathrm{H}_{47} \mathrm{ClN}$ & 388,7 & 3,2 & & \\
\hline Terbutryn & & $886-50-0$ & $\mathrm{C}_{10} \mathrm{H}_{19} \mathrm{~N}_{5} \mathrm{~S}$ & 241,4 & 3,7 & 4,3 & 0,034 \\
\hline $\begin{array}{c}\text { Cybutryn (Irgarol } \\
\text { 1051) } \\
\end{array}$ & & 28159-98-0 & $\mathrm{C}_{11} \mathrm{H}_{19} \mathrm{~N}_{5} \mathrm{~S}$ & 253,4 & 3,7 & 4,1 & 0,001 \\
\hline Terbuthylazine & & $5915-41-3$ & $\mathrm{C}_{9} \mathrm{H}_{16} \mathrm{ClN} 5$ & 229,7 & 3.0 & 2 & 0,06 \\
\hline Carbendazim & & $10605-21-7$ & $\mathrm{C}_{9} \mathrm{H}_{9} \mathrm{~N}_{3} \mathrm{O}_{2}$ & 191,2 & 1,5 & 4,2 & 0,034 \\
\hline $\begin{array}{c}\text { Iodopropynyl } \\
\text { butylcarbamate }\end{array}$ & IPBC & 55406-53-6 & $\mathrm{C}_{8} \mathrm{H}_{12} \mathrm{INO}_{2}$ & 281,1 & 2,8 & & 0,026 \\
\hline Thiabendazole & & $148-79-8$ & $\mathrm{C}_{10} \mathrm{H}_{7} \mathrm{~N}_{3} \mathrm{~S}$ & 201,2 & 2,4 & $4,7 \& 12$ & 1,2 \\
\hline Tebuconazole & & 107534-96-3 & $\mathrm{C}_{16} \mathrm{H}_{22} \mathrm{ClN}_{3} \mathrm{O}$ & 307,8 & 3,7 & 5 & 1 \\
\hline Mecoprop & & $93-65-2$ & $\mathrm{C}_{10} \mathrm{H}_{11} \mathrm{ClO}_{3}$ & 214,6 & 0,1 & 3,7 & 44 \\
\hline
\end{tabular}

MW: molecular weight

PNEC: predicted no effect concentration 
Table S2 Optimized SPE protocol

\begin{tabular}{|c|c|}
\hline Step & Description \\
\hline Pre step & Acidification of the sample ( $0.1 \%$ formic acid) \\
\hline $\begin{array}{l}\text { Conditioning of the HR-X cartridge } \\
(200 \mathrm{mg}, 6 \mathrm{~mL})\end{array}$ & $\begin{array}{ll}\text { (i) } & 5 \mathrm{~mL} \text { DCM } \\
\text { (ii) } & 10 \mathrm{~mL} \mathrm{EtAc} \\
\text { (iii) } & 10 \mathrm{~mL} \mathrm{MeOH} \\
\text { (iv) } & 10 \mathrm{~mL} \mathrm{UP} \mathrm{water}+0.1 \% \mathrm{HCOOH}\end{array}$ \\
\hline Load sample & $10 \mathrm{~mL} / \mathrm{min}$ \\
\hline Washing & $2 \mathrm{~mL} \mathrm{UP}$ water $+0.1 \% \mathrm{HCOOH}$ \\
\hline Drying under $\mathrm{N}_{2}$ & $30 \mathrm{~min}$ \\
\hline Elution & $\begin{array}{ll}\text { (i) } & 6 \mathrm{~mL} \mathrm{MeOH} \\
\text { (ii) } & 3 \mathrm{~mL} \mathrm{EtAc} \\
\text { (iii) } & 2 \mathrm{~mL} \mathrm{DCM}\end{array}$ \\
\hline Post step & $\begin{array}{l}\text { Storage at }-8^{\circ} \mathrm{C} \text { in freezer } \\
\text { Evaporation under nitrogen flow } \\
\text { Filtration through a } 0.2 \mu \mathrm{m} \text { syringe filter } \\
\text { Addition of injection internal standards } \\
\text { Final volume before injection: } 1 \mathrm{~mL} \text { of } \\
\text { mobile phase }(80 \% \text { acidified UP water and } \\
20 \% \text { acidified } \mathrm{MeOH})\end{array}$ \\
\hline
\end{tabular}


Table S3 Optimized particulate extraction

\begin{tabular}{|c|c|}
\hline Step & Description \\
\hline Preparation of the sample & $\begin{array}{l}\text { Cutting of the filter into small pieces } \\
\text { Addition of } 20 \mathrm{~mL} \text { of } \mathrm{MeOH} / \mathrm{DCM}(60 / 40 \mathrm{v} / \mathrm{v})\end{array}$ \\
\hline $\begin{array}{l}\text { Microwaves assisted extraction } \\
\text { Cycle } 1\end{array}$ & $\begin{array}{l}0-5 \text { min: from room temperature to } 100^{\circ} \mathrm{C} \\
\text { 5-10 min: } 100^{\circ} \mathrm{C} \\
\text { Cooling }\end{array}$ \\
\hline Filtration of the extract & $\begin{array}{l}\text { Through a pleated filter previously dampened } \\
\text { then rinsed with } 4 \mathrm{~mL} \text { of extraction solvent }\end{array}$ \\
\hline $\begin{array}{l}\text { Microwaves assisted extraction } \\
\text { Cycle } 2\end{array}$ & $\begin{array}{l}\text { Addition of } 20 \mathrm{~mL} \text { of extraction solvent, second } \\
\text { cycle of extraction and filtration of the extract }\end{array}$ \\
\hline Pre evaporation & With a Rotavapor (Büchi) until $4 \mathrm{~mL}$ \\
\hline Post step & $\begin{array}{l}\text { Storage at }-8^{\circ} \mathrm{C} \text { in freezer } \\
\text { Evaporation under nitrogen flow } \\
\text { Filtration through a } 0.2 \mu \mathrm{m} \text { syringe filter } \\
\text { Addition of injection internal standards } \\
\text { Final volume before injection: } 1 \mathrm{~mL} \text { of mobile } \\
\text { phase }(80 \% \text { acidified UP water and } 20 \% \\
\text { acidified } \mathrm{MeOH})\end{array}$ \\
\hline
\end{tabular}


Table S4 MS parameters

\begin{tabular}{|c|c|}
\hline MS parameters & Set values \\
\hline Capillary voltage & $\begin{array}{r}0,8 \mathrm{kV} \text { in positive mode } \\
-2,3 \mathrm{kV} \text { in negative mode }\end{array}$ \\
\hline Extractor voltage & $3 \mathrm{~V}$ \\
\hline Radio frequency lens & $0.1 \mathrm{~V}$ \\
\hline Source temperature & $150^{\circ} \mathrm{C}$ \\
\hline Desolvatation tempreature & $400^{\circ} \mathrm{C}$ \\
\hline Desolvatation gas flow & $600 \mathrm{~L} / \mathrm{h}$ \\
\hline Cone gas flow & $50 \mathrm{~L} / \mathrm{h}$ \\
\hline
\end{tabular}



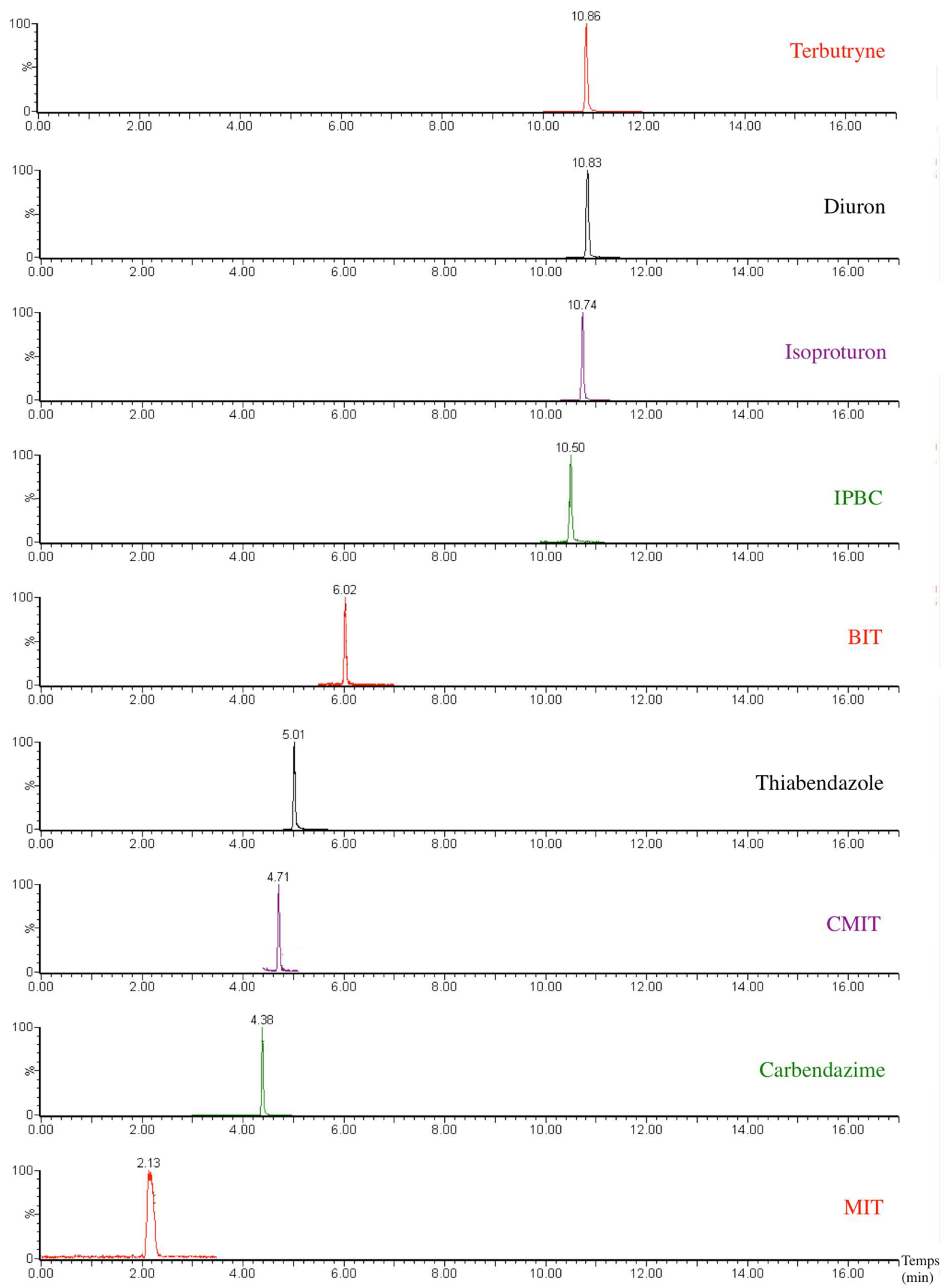

Fig. S1 Chromatograms obtained with the developed HPLC-MS/MS method (mobile phase A/B, $80 / 20$, spiked at $10 \mu \mathrm{g} / \mathrm{L})(1 / 2)$ 

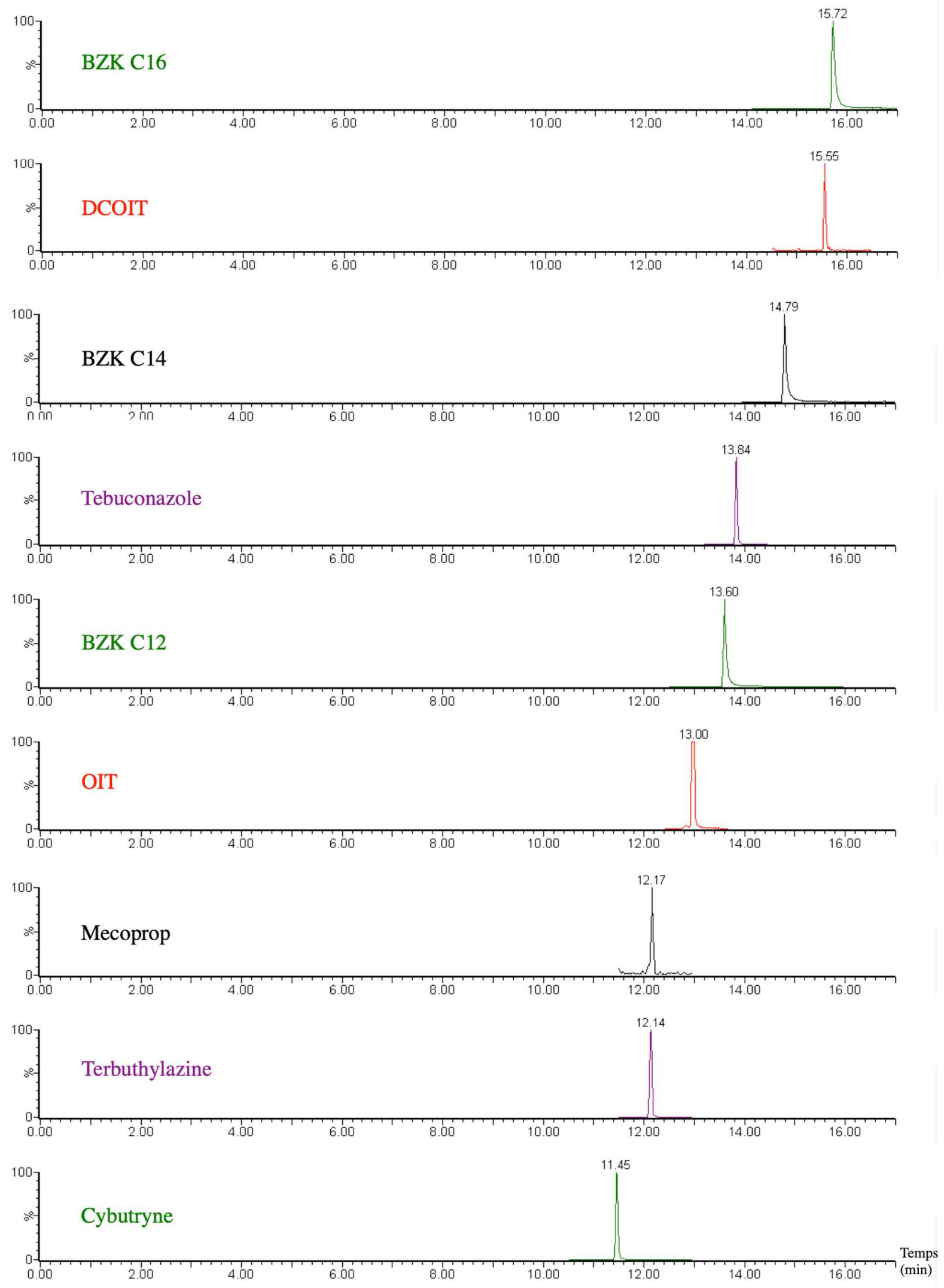

Fig. S2 Chromatograms obtained with the developed HPLC-MS/MS method (mobile phase A/B, $80 / 20$, spiked at $10 \mu \mathrm{g} / \mathrm{L})(2 / 2)$ 

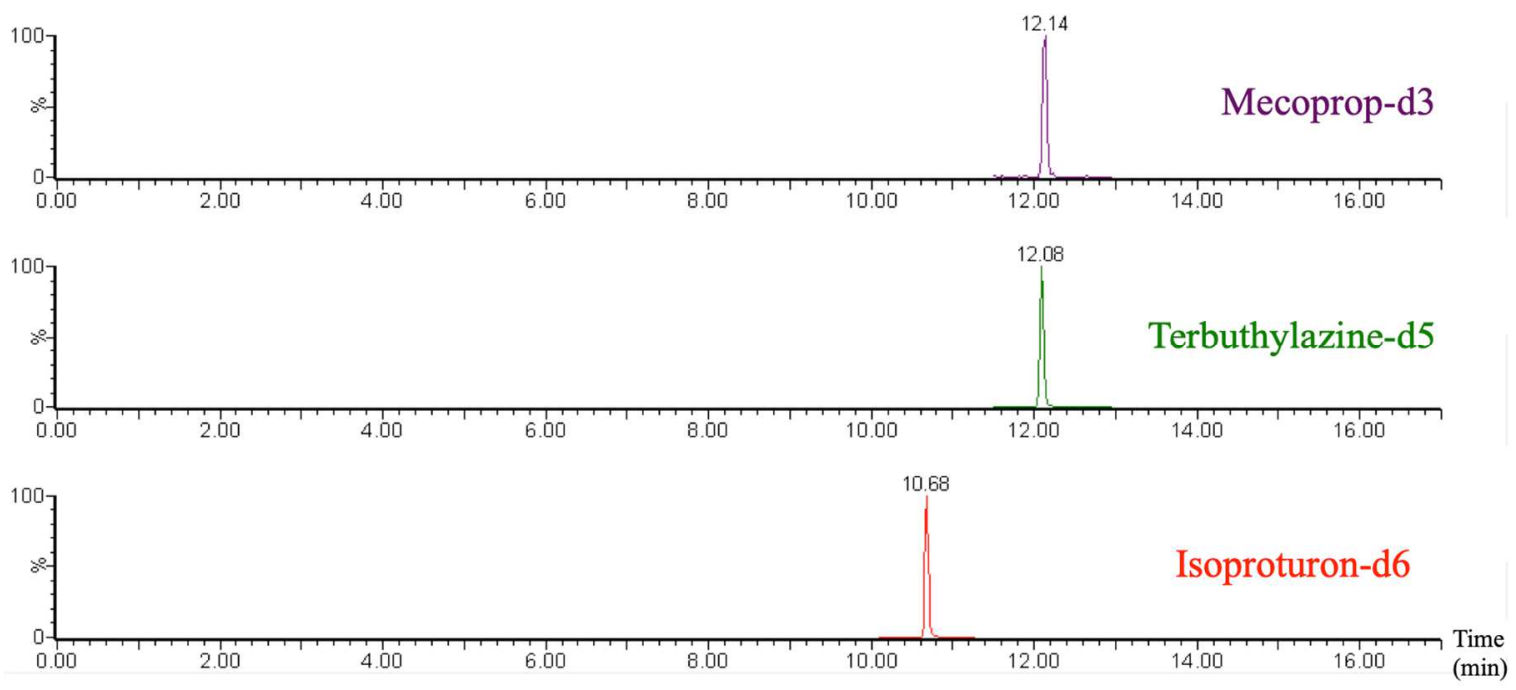

Fig. S3 Chromatograms of internal standards obtained with the developed HPLC-MS/MS method (mobile phase $\mathrm{A} / \mathrm{B}, 80 / 20$, spiked at $50 \mu \mathrm{g} / \mathrm{L}$ )

Table S5 Spiking concentration for the determination of SPE recoveries

\begin{tabular}{|c|c|c|}
\hline Matrix & $\begin{array}{c}\text { Concentrations of biocides } \\
(\mathbf{n g} / \mathbf{L})\end{array}$ & $\begin{array}{c}\text { Concentrations of } \\
\text { benzalkoniums }(\boldsymbol{\mu g} / \mathbf{L})\end{array}$ \\
\hline Combined sewer overflows & $50 ; 100 ; 250$ & $10 ; 20$ \\
\hline Stormwater & $50 ; 125 ; 375$ & - \\
\hline Untreated wastewater & $50 ; 100 ; 250$ & $2.5 ; 10$ \\
\hline Treated wastewater & $25 ; 50 ; 125$ & $0.125 ; 1.25$ \\
\hline Surface waters & $10 ; 20 ; 50$ & $50 ; 500$ \\
\hline
\end{tabular}
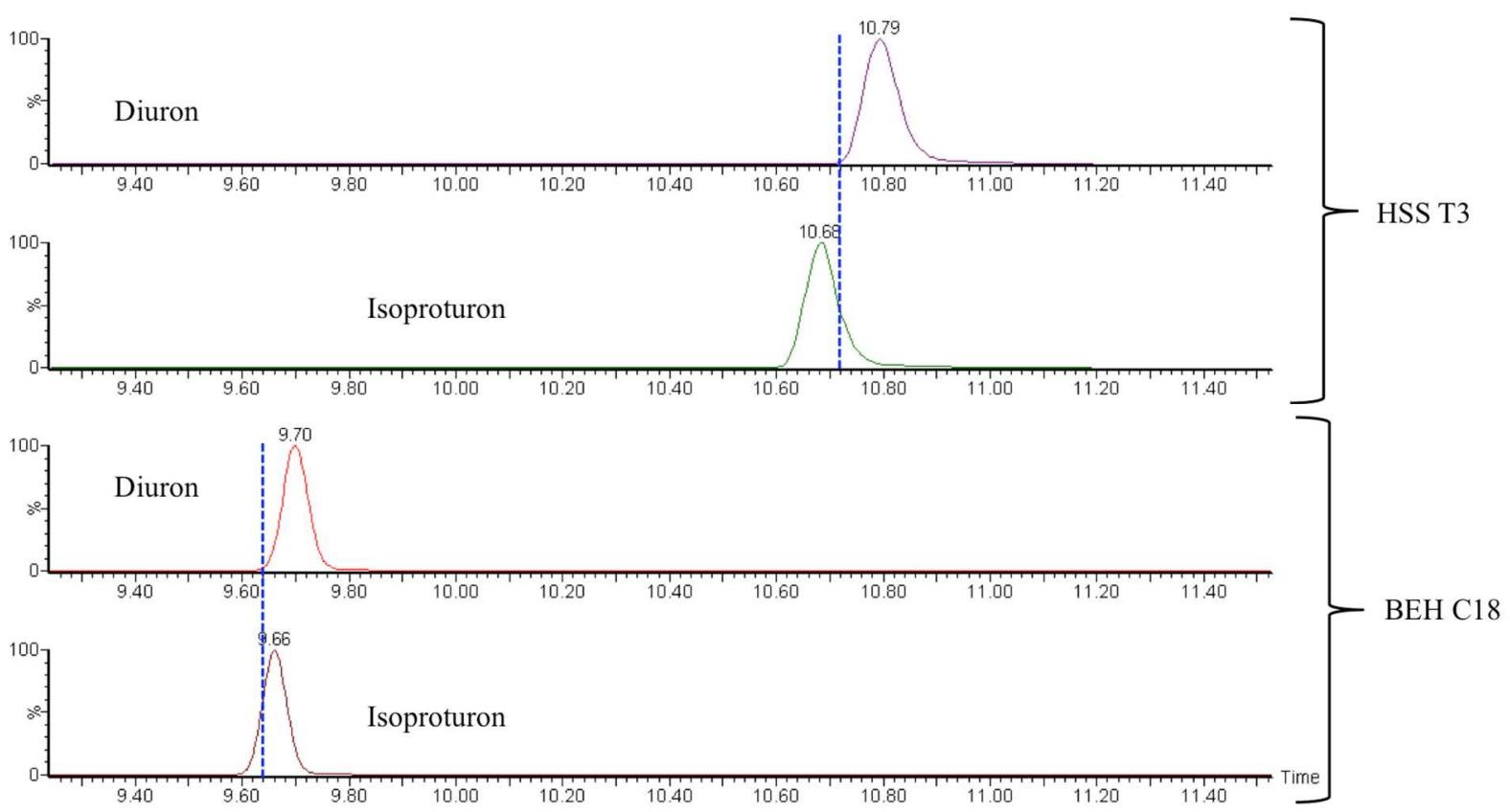

Fig. S4 Comparison of chromatograms of diuron and isoproturon obtained with HSS T3 column and BEH C18 column 


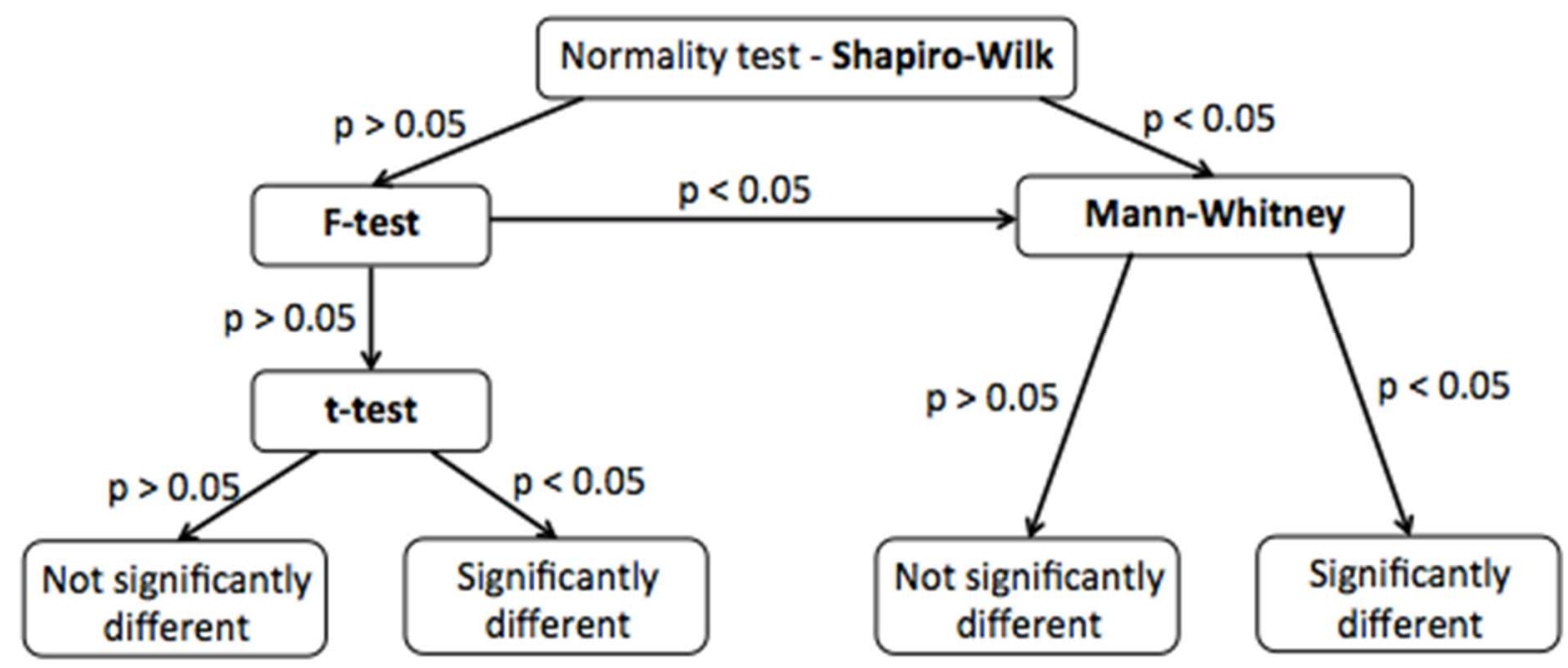

Fig. S5 Statistical tests, which were performed in order to compare SPE cartridges

Table S6 Comparison of the two SPE cartridges - Results of the statistical tests

\begin{tabular}{|c|c|c|c|c|c|c|}
\hline \multirow{3}{*}{ Biocides } & \multirow{2}{*}{\multicolumn{2}{|c|}{$\begin{array}{c}\text { Normality (Shapiro-Wilk) } \\
\text { p value }\end{array}$}} & \multirow{3}{*}{$\begin{array}{c}\begin{array}{c}\text { Homogeneity } \\
\text { of variances } \\
\text { (F-test) }\end{array} \\
\text { p value }\end{array}$} & \multicolumn{3}{|c|}{$\begin{array}{l}\text { Equality of means (T-test) or medians (Mann- } \\
\text { Whitney) }\end{array}$} \\
\hline & & & & \multirow{2}{*}{ Test } & \multirow{2}{*}{$p$ value } & \multirow{2}{*}{ Conclusion } \\
\hline & HLB & HR-X & & & & \\
\hline Diuron & 0.91 & 0.51 & 0.67 & Test $\mathrm{t}$ & 0.42 & Equality \\
\hline Isoproturon & 0.62 & 0.70 & 0.28 & Test $\mathrm{t}$ & 0.25 & Equality \\
\hline MIT & 0.34 & 0.71 & 0.93 & Test t & 1.8E-09 & HR-X > HLB \\
\hline BIT & 0.92 & 0.54 & 0.37 & Test $\mathrm{t}$ & 0.92 & Equality \\
\hline CMIT & 0.06 & 0.04 & & Mann-Whitney & 0.01 & HR-X > HLB \\
\hline OIT & 0.48 & 0.53 & 0.69 & Test $\mathrm{t}$ & 0.82 & Equality \\
\hline DCOIT & 0.32 & 0.46 & 0.40 & Test $\mathrm{t}$ & 0.17 & Equality \\
\hline BZK C12 & 0.64 & 0.72 & 0.75 & Test $\mathrm{t}$ & 0.18 & Equality \\
\hline BZK C14 & 0.01 & 0.99 & & Mann-Whitney & 0.02 & HR-X > HLB \\
\hline BZK C16 & 0.12 & 0.34 & 0.06 & Test t & 0.66 & Equality \\
\hline Terbutryn & 0.22 & 0.57 & 0.18 & Test $\mathrm{t}$ & 0.21 & Equality \\
\hline Cybutryn & 0.39 & 0.52 & 4.8E-04 & Mann-Whitney & 0.008 & HR-X > HLB \\
\hline Terbuthylazine & 0.75 & 0.45 & 0.21 & Test t & 0.02 & HR-X > HLB \\
\hline Carbendazim & 0.70 & 0.03 & & Mann-Whitney & 0.13 & Equality \\
\hline IPBC & 0.44 & 0.56 & 0.67 & Test $\mathrm{t}$ & 0.25 & Equality \\
\hline Thiabendazole & 0.74 & 0.90 & 0.10 & Test $\mathrm{t}$ & 0.01 & HR-X > HLB \\
\hline Tebuconazole & 0.80 & 0.97 & 0.51 & Test $\mathrm{t}$ & 0.92 & Equality \\
\hline Mecoprop & 0.50 & 0.11 & 0.50 & Test $\mathrm{t}$ & 0.18 & Equality \\
\hline
\end{tabular}




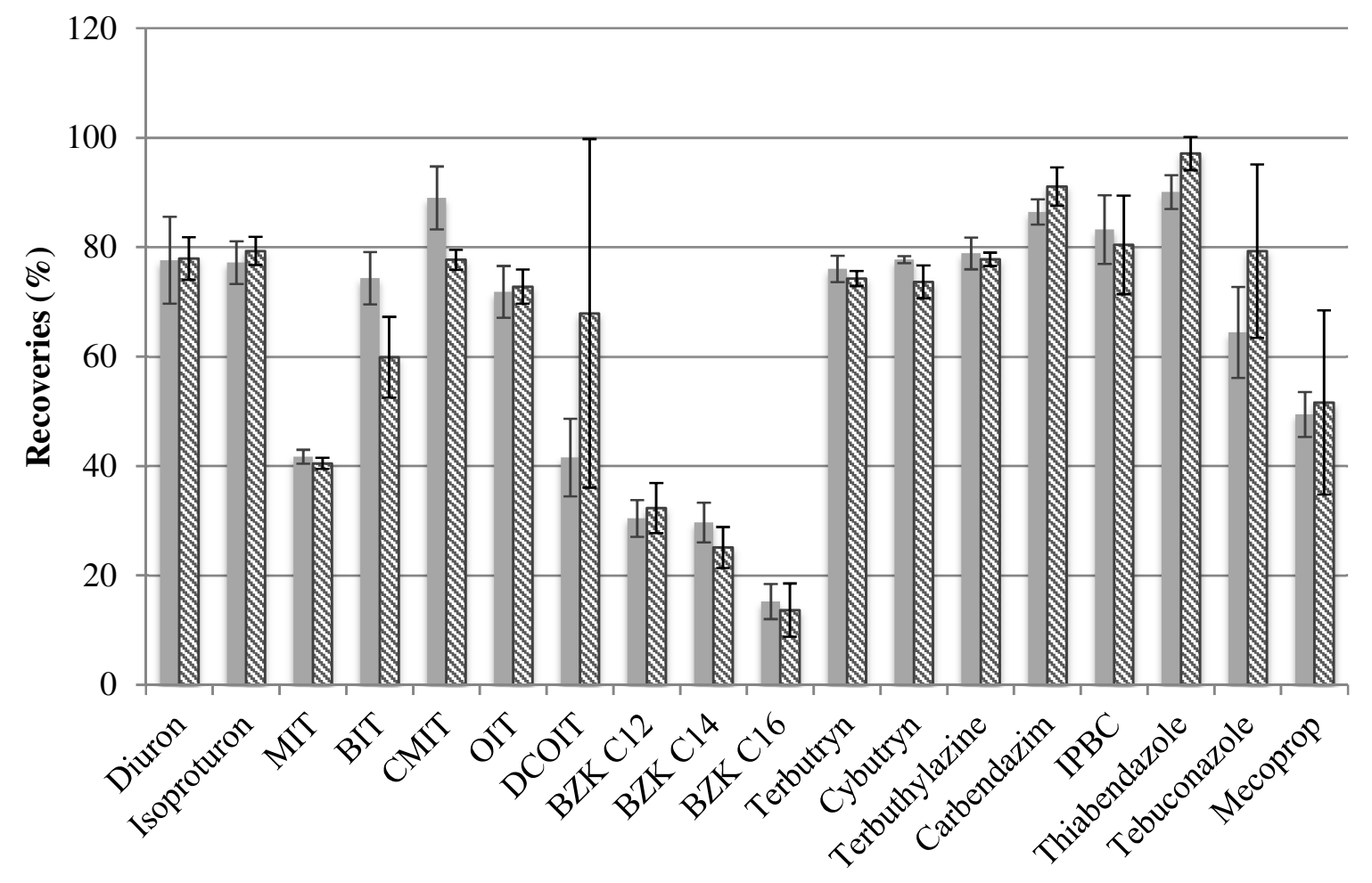

Elution with $6 \mathrm{~mL} \mathrm{MeOH}, 3 \mathrm{~mL}$ EtAc and $2 \mathrm{~mL}$ DCM

Elution with $6 \mathrm{~mL} \mathrm{MeOH}$ and $3 \mathrm{~mL}$ EtAc

Fig. S6 SPE recoveries obtained with two different elution procedures $(100 \mathrm{~mL}$ of UP water spiked at $100 \mathrm{ng} / \mathrm{L}, \mathrm{n}=3$ )

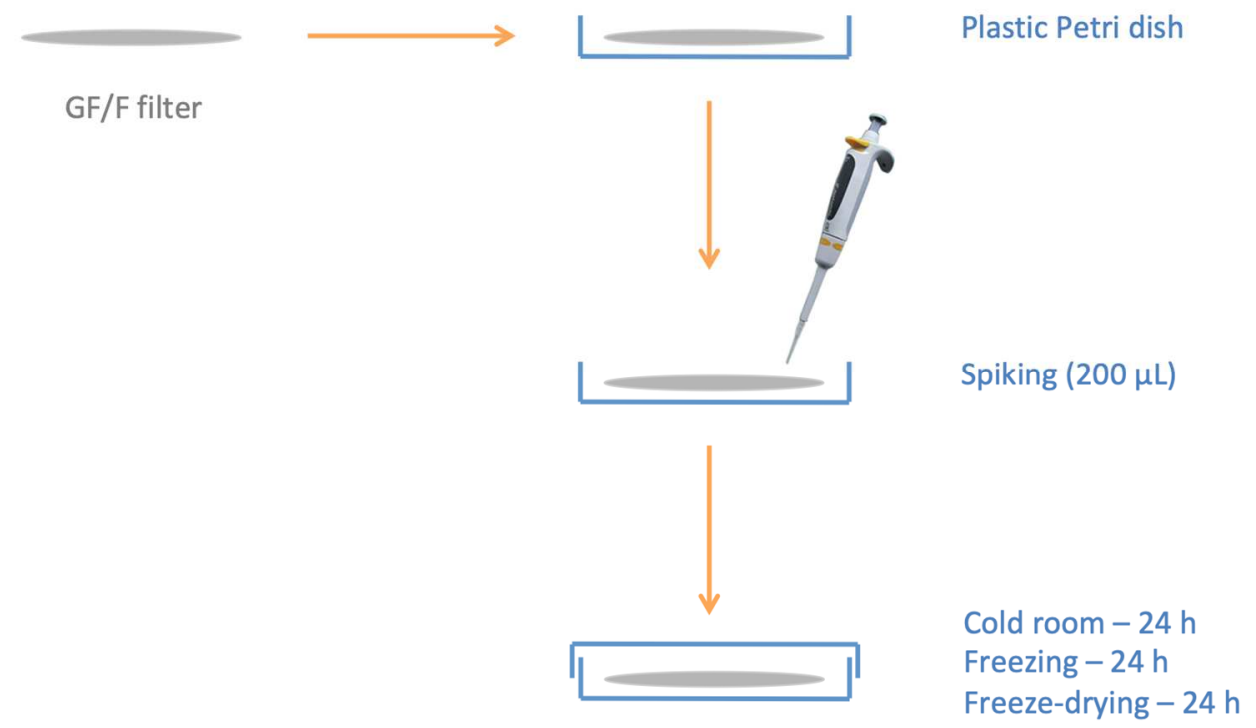

Fig. S7 Spiking procedure for MAE optimizations 


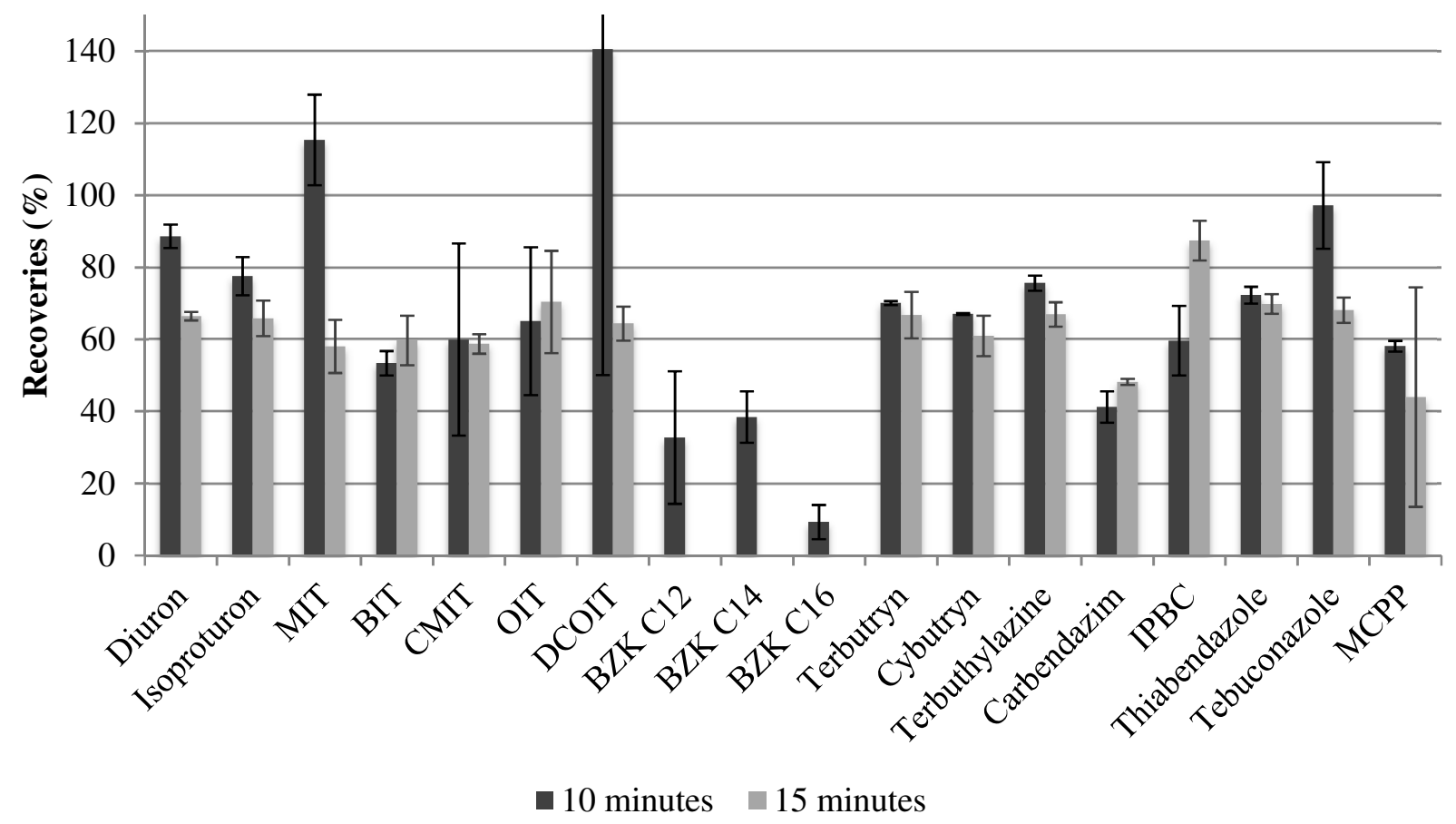

Fig. S8 MAE recoveries of biocides obtained with two different extraction time (extraction at $100^{\circ} \mathrm{C}$ in $\mathrm{MeOH} / \mathrm{DCM} 60 / 40 \mathrm{v} / \mathrm{v}, \mathrm{n}=3$ )

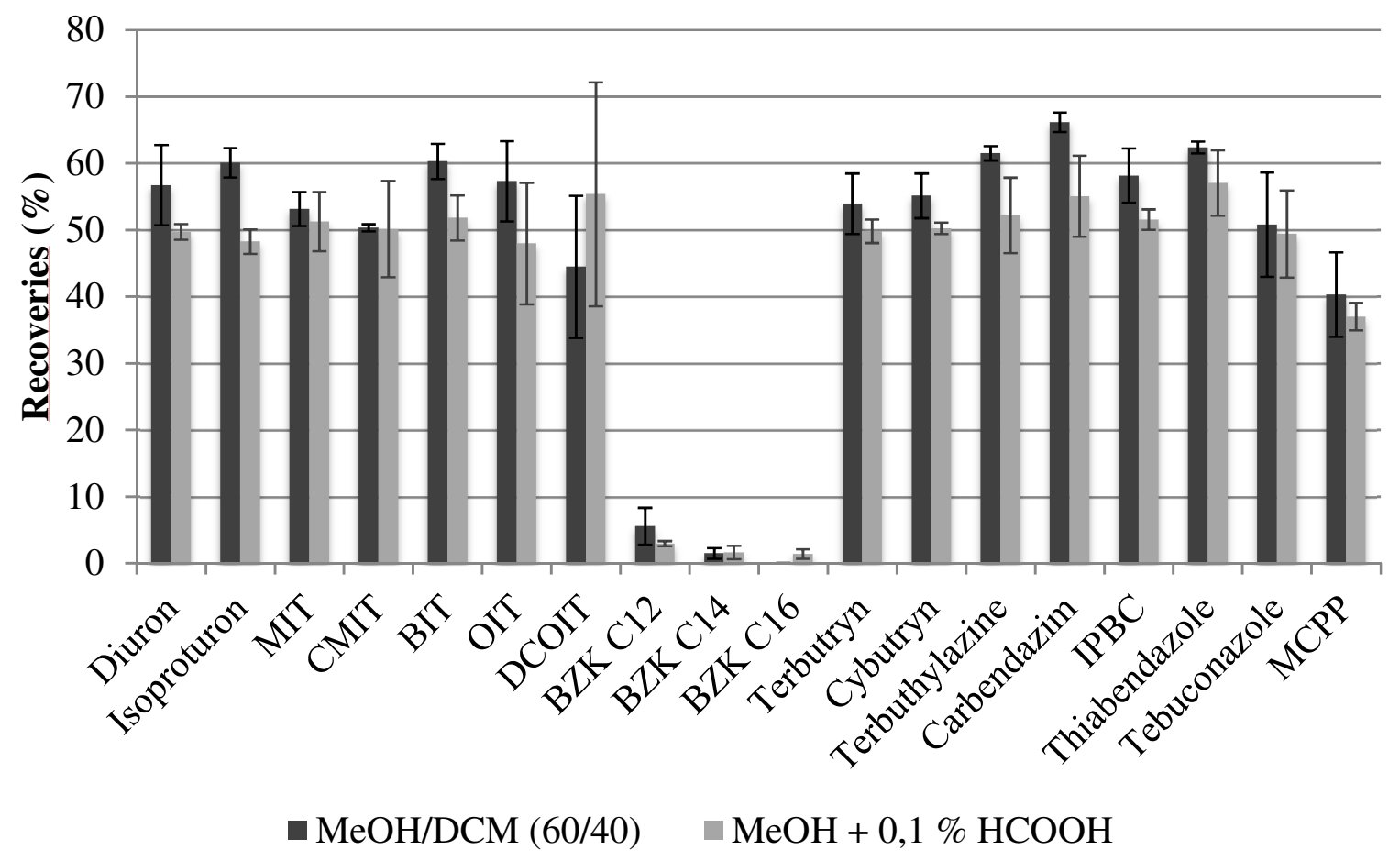

Fig. S9 MAE recoveries of biocides obtained with two different extraction solvents (extraction at $100^{\circ} \mathrm{C}$ with a temperature plateau of $10 \mathrm{~min}, \mathrm{n}=3$ ) 
Table S7 HPLC-MS/MS linearity ranges

\begin{tabular}{|c|c|c|c|c|c|c|c|c|}
\hline \multirow[b]{2}{*}{ Biocides } & \multicolumn{4}{|c|}{ Linearity range 1} & \multicolumn{4}{|c|}{ Linearity range 2} \\
\hline & $\begin{array}{c}\text { Concentrations } \\
(\mu \mathrm{g} / \mathrm{L})\end{array}$ & $\mathbf{R}^{2}$ & slope & intercept & $\begin{array}{c}\text { Concentrations } \\
(\mu \mathrm{g} / \mathrm{L})\end{array}$ & $\mathbf{R}^{2}$ & slope & intercept \\
\hline Diuron & $0.1-50$ & 0.997 & $2.7 \mathrm{E}-03$ & $1.1 \mathrm{E}-03$ & & & & \\
\hline Isoproturon & $0.05-10$ & 0.999 & $1.6 \mathrm{E}-02$ & $-3.4 \mathrm{E}-04$ & $10-150$ & 0.999 & $1.6 \mathrm{E}-02$ & $-2.1 \mathrm{E}-02$ \\
\hline MIT & $0.5-50$ & 0.997 & $4.3 \mathrm{E}-05$ & $1.3 \mathrm{E}-05$ & & & & \\
\hline BIT & $0.05-10$ & 0.998 & $8.5 \mathrm{E}-04$ & $-7.0 \mathrm{E}-05$ & $10-150$ & 0.998 & 9.7E-04 & $-1.7 \mathrm{E}-03$ \\
\hline CMIT & $1-150$ & 0.998 & $2.0 \mathrm{E}-05$ & $-3.0 \mathrm{E}-05$ & & & & \\
\hline OIT & $0.05-10$ & 0.999 & $1.1 \mathrm{E}-02$ & $2.6 \mathrm{E}-03$ & $10-150$ & 0.997 & $1.3 \mathrm{E}-02$ & $-8.8 \mathrm{E}-02$ \\
\hline DCOIT & $0.25-10$ & 0.991 & $4.0 \mathrm{E}-02$ & $-4.2 \mathrm{E}-03$ & $10-150$ & 0.994 & $9.0 \mathrm{E}-04$ & $-1.2 \mathrm{E}-02$ \\
\hline BZK C12 & $1-250$ & 0.998 & $3.1 \mathrm{E}-02$ & $-9.9 \mathrm{E}-02$ & & & & \\
\hline BZK C14 & $1-150$ & 0.987 & $1.7 \mathrm{E}-02$ & $-6.1 \mathrm{E}-02$ & & & & \\
\hline BZK C16 & $1-250$ & 0.996 & $1.1 \mathrm{E}-02$ & $-5.6 \mathrm{E}-02$ & & & & \\
\hline Terbutryn & $0.05-10$ & 1.000 & $2.0 \mathrm{E}-02$ & $-2.0 \mathrm{E}-04$ & $10-150$ & 0.998 & $2.1 \mathrm{E}-02$ & $-4.6 \mathrm{E}-02$ \\
\hline Cybutryn & $0.05-10$ & 1.000 & $2.0 \mathrm{E}-02$ & $-1.7 \mathrm{E}-04$ & $10-150$ & 0.999 & $2.1 \mathrm{E}-02$ & $-3.6 \mathrm{E}-02$ \\
\hline Terbuthylazine & $0.05-10$ & 1.000 & $1.5 \mathrm{E}-02$ & $-1.4 \mathrm{E}-04$ & $10-150$ & 0.998 & $1.5 \mathrm{E}-02$ & $-2.9 \mathrm{E}-02$ \\
\hline Carbendazim & $0.05-10$ & 0.999 & $1.2 \mathrm{E}-02$ & $5.7 \mathrm{E}-03$ & $10-150$ & 0.999 & $1.1 \mathrm{E}-02$ & 4.7E-03 \\
\hline IPBC & $0.25-10$ & 0.998 & $6.3 \mathrm{E}-04$ & $-9.0 \mathrm{E}-05$ & $10-150$ & 0.997 & $8.0 \mathrm{E}-04$ & $-4.0 \mathrm{E}-03$ \\
\hline Thiabendazole & $0.05-10$ & 0.999 & $5.0 \mathrm{E}-03$ & $-2.1 \mathrm{E}-04$ & $10-150$ & 0.999 & $5.0 \mathrm{E}-03$ & $-7.5 \mathrm{E}-03$ \\
\hline Tebuconazole & $0.05-10$ & 0.999 & $6.1 \mathrm{E}-03$ & $-1.8 \mathrm{E}-04$ & $10-150$ & 0.996 & $8.2 \mathrm{E}-03$ & $-5.1 \mathrm{E}-02$ \\
\hline
\end{tabular}


Table S8 HPLC-MS/MS repeatability

\begin{tabular}{|c|c|c|}
\hline \multirow{2}{*}{ Biocides } & \multicolumn{2}{|c|}{ RSDs (\%) } \\
\cline { 2 - 3 } & $\mathbf{1 0} \boldsymbol{\mu g} / \mathbf{L}$ & $\mathbf{7 5} \boldsymbol{\mu g} / \mathbf{L}$ \\
\hline Diuron & 6.4 & 4.4 \\
\hline Isoproturon & 2.1 & 3.9 \\
\hline MIT & 7.4 & 3.7 \\
\hline BIT & 4.2 & 4.4 \\
\hline CMIT & 18 & 5.9 \\
\hline OIT & 4.3 & 3.8 \\
\hline DCOIT & 16 & 13 \\
\hline BZK C12 & 9.2 & 6.1 \\
\hline BZK C14 & 9.3 & 3.6 \\
\hline BZK C16 & 7.2 & 6.5 \\
\hline Terbutryn & 6.4 & 3.9 \\
\hline Cybutryn & 6.7 & 4.5 \\
\hline Terbuthylazine & 4.8 & 3.4 \\
\hline Carbendazim & 12 & 9.7 \\
\hline IPBC & 9.4 & 2.1 \\
\hline Thiabendazole & 13 & 9.3 \\
\hline Tebuconazole & 9.2 & 6.1 \\
\hline Mecoprop & 25 & 24 \\
\hline
\end{tabular}

Table S9 Matrix effects

\begin{tabular}{|c|c|c|c|c|c|c|c|c|c|c|}
\cline { 2 - 10 } \multicolumn{1}{c|}{} & \multicolumn{1}{c|}{ Surface water } & \multicolumn{2}{c|}{ WWTP effluents } & \multicolumn{2}{c|}{ WWTP influents } & \multicolumn{2}{c|}{ Stormwater } & \multicolumn{2}{c|}{ CSOs } \\
\cline { 2 - 11 } & D & P & D & P & D & P & D & P & D & P \\
\hline $\begin{array}{c}\text { Isoprotur } \\
\text { on-d6 }\end{array}$ & $-3 \%$ & $+1 \%$ & $-4 \%$ & $-8 \%$ & $-26 \%$ & $-3 \%$ & $-8 \%$ & $+21 \%$ & $-12 \%$ & $-1 \%$ \\
\hline $\begin{array}{c}\text { Terbuthy } \\
\text { lazine-d5 }\end{array}$ & $+9 \%$ & $0 \%$ & $+9 \%$ & $-4 \%$ & $-18 \%$ & $+2 \%$ & $-3 \%$ & $+16 \%$ & $+5 \%$ & $-1 \%$ \\
\hline $\begin{array}{c}\text { Mecopro } \\
\text { p-d3 }\end{array}$ & $-33 \%$ & $-28 \%$ & $-19 \%$ & $-31 \%$ & $-31 \%$ & $+15 \%$ & $-32 \%$ & $+19 \%$ & $+36 \%$ & $-2 \%$ \\
\hline
\end{tabular}


Table S10 Limits of detection (LOD) and quantification (LOQ) in the dissolved fraction of urban and surface waters in ng/L

\begin{tabular}{|c|c|c|c|c|c|c|c|c|c|c|c|c|}
\hline \multirow[b]{2}{*}{ Biocides } & \multicolumn{2}{|c|}{ Instrumental } & \multicolumn{2}{|c|}{ Surface water/rain } & \multicolumn{2}{|c|}{ WWTP effluents } & \multicolumn{2}{|c|}{ WWTP influents } & \multicolumn{2}{|c|}{ Stormwater } & \multicolumn{2}{|c|}{ CSOs } \\
\hline & $\begin{array}{c}\text { LOD } \\
(\mu \mathrm{g} / \mathrm{L})\end{array}$ & $\begin{array}{c}\text { LOQ } \\
(\mu \mathrm{g} / \mathrm{L})\end{array}$ & $\begin{array}{c}\text { LOD } \\
\text { (ng/L) }\end{array}$ & $\begin{array}{c}\text { LOQ } \\
(\mathrm{ng} / \mathrm{L})\end{array}$ & $\begin{array}{c}\text { LOD } \\
(\mathrm{ng} / \mathrm{L})\end{array}$ & $\begin{array}{c}\text { LOQ } \\
\text { (ng/L) }\end{array}$ & $\begin{array}{c}\text { LOD } \\
\text { (ng/L) }\end{array}$ & $\begin{array}{c}\text { LOQ } \\
\text { (ng/L) }\end{array}$ & $\begin{array}{c}\text { LOD } \\
\text { (ng/L) }\end{array}$ & $\begin{array}{c}\text { LOQ } \\
(\mathrm{ng} / \mathrm{L})\end{array}$ & $\begin{array}{c}\text { LOD } \\
\text { (ng/L) }\end{array}$ & $\begin{array}{c}\text { LOQ } \\
\text { (ng/L) }\end{array}$ \\
\hline Diuron & 0.05 & 0.25 & 0.27 & 0.66 & 0.50 & 1.3 & 1.2 & 3.1 & 0.76 & 1.9 & 1.3 & 3.2 \\
\hline Isoproturon & 0.05 & 0.05 & 0.11 & 0.11 & 0.21 & 2.1 & 0.44 & 0.44 & 0.34 & 0.34 & 0.56 & 0.56 \\
\hline MIT & 0.25 & 0.50 & 5.0 & 9.9 & 9.2 & 18 & 13 & 26 & 6.1 & 12 & 9.7 & 19 \\
\hline BIT & 0.10 & 0.75 & 0.28 & 2.1 & 0.58 & 4.3 & 0.98 & 7.3 & 0.65 & 4.9 & 1.4 & 10 \\
\hline CMIT & 0.50 & 2.5 & 1.6 & 8.0 & 3.14 & 16 & 11 & 54 & 4.5 & 23 & 7.6 & 38 \\
\hline OIT & 0.10 & 0.25 & 0.21 & 0.52 & 0.49 & 1.2 & 1.3 & 3.2 & 0.93 & 2.31 & 1.3 & 3.3 \\
\hline DCOIT & 0.05 & 0.50 & 0.04 & 0.45 & 0.11 & 1.1 & 0.36 & 3.6 & 0.23 & 2.32 & 0.27 & 2.7 \\
\hline BZK C12 & 0.75 & 2.5 & 5.0 & 17 & 8.1 & 27 & 22 & 73 & 18 & 59 & 22 & 73 \\
\hline BZK C14 & 0.75 & 2.5 & 4.7 & 16 & 11 & 37 & 37 & 123 & 15 & 50 & 25 & 84 \\
\hline BZK C16 & 0.75 & 2.5 & 3.6 & 12 & 7.5 & 25 & 20 & 68 & 57 & 190 & 110 & 360 \\
\hline Terbutryn & 0.05 & 0.05 & 0.13 & 0.13 & 0.23 & 0.23 & 0.51 & 0.51 & 0.43 & 0.43 & 0.63 & 0.63 \\
\hline Cybutryn & 0.05 & 0.05 & 0.14 & 0.14 & 0.27 & 0.27 & 0.62 & 0.62 & 0.48 & 0.48 & 0.67 & 0.67 \\
\hline Terbuthylazine & 0.05 & 0.05 & 0.11 & 0.11 & 0.23 & 0.23 & 0.52 & 0.52 & 0.44 & 0.44 & 0.67 & 0.67 \\
\hline Carbendazim & 0.05 & 0.05 & 0.17 & 0.17 & 0.31 & 0.31 & 0.61 & 0.61 & 0.44 & 0.44 & 0.72 & 0.72 \\
\hline IPBC & 0.50 & 1.0 & 1.2 & 2.4 & 2.2 & 4.3 & 5.0 & 10 & 3.2 & 6.3 & 5.1 & 10 \\
\hline Thiabendazole & 0.05 & 0.05 & 0.15 & 0.15 & 0.27 & 0.27 & 0.58 & 0.58 & 0.42 & 0.42 & 0.69 & 0.69 \\
\hline Tebuconazole & 0.05 & 0.05 & 0.08 & 0.08 & 0.18 & 0.18 & 0.38 & 0.38 & 0.38 & 0.38 & 0.55 & 0.55 \\
\hline Mecoprop & 0.75 & 1.0 & 1.5 & 2.0 & 3.1 & 4.1 & 6.8 & 9.1 & 2.9 & 3.9 & 7.0 & 9.3 \\
\hline
\end{tabular}


Table S11 Limits of detection (LOD) and quantification (LOQ) (min-max) in the particulate fraction of urban and surface waters in ng/g (dry weight)

\begin{tabular}{|c|c|c|c|c|c|c|c|c|c|c|}
\hline \multirow{3}{*}{$\begin{array}{c}\text { Mass of } \\
\text { particles (mg) }\end{array}$} & \multicolumn{2}{|c|}{ Surface water } & \multicolumn{2}{|c|}{ WWTP effluents } & \multicolumn{2}{|c|}{ WWTP influents } & \multicolumn{2}{|c|}{ Stormwater } & \multicolumn{2}{|c|}{ CSOs } \\
\hline & $\begin{array}{l}\text { LOD } \\
\text { (ng/g) }\end{array}$ & $\begin{array}{c}\text { LOQ } \\
\text { (ng/g) }\end{array}$ & $\begin{array}{l}\text { LOD } \\
\text { (ng/g) }\end{array}$ & $\begin{array}{c}\text { LOQ } \\
\text { (ng/g) }\end{array}$ & $\begin{array}{l}\text { LOD } \\
\text { (ng/g) }\end{array}$ & $\begin{array}{c}\text { LOQ } \\
\text { (ng/g) }\end{array}$ & $\begin{array}{c}\text { LOD } \\
\text { (ng/g) }\end{array}$ & $\begin{array}{c}\text { LOQ } \\
\text { (ng/g) }\end{array}$ & $\begin{array}{l}\text { LOD } \\
\text { (ng/g) }\end{array}$ & $\begin{array}{c}\text { LOQ } \\
\text { (ng/g) }\end{array}$ \\
\hline & \multicolumn{2}{|c|}{$8,5-103$} & \multicolumn{2}{|c|}{$4,3-11$} & \multicolumn{2}{|c|}{$54-84$} & \multicolumn{2}{|c|}{$28-84$} & \multicolumn{2}{|c|}{$27-130$} \\
\hline Diuron & $1.0-1.2$ & $2.4-30$ & $9.0-23$ & $23-58$ & $1.0-2.0$ & $3.0-5.0$ & $1.0-4.0$ & $3.0-9.0$ & $0.8-3.7$ & $1.9-9.2$ \\
\hline Isoproturon & $0.5-5.9$ & $0.5-5.9$ & $5.0-12$ & $5.0-12$ & 1.0 & 1.0 & $1.0-2.0$ & $1.0-2.0$ & $0.4-1.8$ & $0.4-1.8$ \\
\hline MIT & $2.4-30$ & 4.9-59 & $23-58$ & $45-120$ & $3.0-5.0$ & $6.0-9.0$ & $3.0-9.0$ & $6.0-18$ & $1.9-9.2$ & $3.9-18$ \\
\hline BIT & $1.0-12$ & 7.3-89 & $9.0-23$ & $68-180$ & $1.0-2.0$ & $9.0-14$ & $1.0-4.0$ & $9.0-27$ & $0.8-3.7$ & $5.8-27$ \\
\hline CMIT & $4.9-59$ & $24-300$ & $45-120$ & $230-580$ & $6.0-9.0$ & $30-47$ & $6.0-18$ & $30-89$ & 3.9-18 & 19-92 \\
\hline OIT & $1.0-12$ & $2.4-30$ & $9.0-23$ & $23-58$ & $1.0-2.0$ & $3.0-5.0$ & $1.0-4.0$ & $3.0-9.0$ & $0.8-3.7$ & $1.9-9.2$ \\
\hline DCOIT & $0.5-5.9$ & 4.9-59 & $5.0-12$ & $45-120$ & 1.0 & $6.0-9.0$ & $1.0-2.0$ & $6.0-18$ & $0.4-1.8$ & $3.9-18$ \\
\hline BZK C12 & $7-90$ & $20-300$ & $70-200$ & $200-600$ & $9-10$ & $30-50$ & $9-30$ & $30-90$ & $6-30$ & $20-90$ \\
\hline BZK C14 & $7-90$ & $20-300$ & $70-200$ & $200-600$ & $9-10$ & $30-50$ & $9-30$ & $30-90$ & $6-30$ & $20-90$ \\
\hline BZK C16 & $7-90$ & $20-300$ & $70-200$ & $200-600$ & $9-10$ & $30-50$ & $9-30$ & $30-90$ & $6-30$ & $20-90$ \\
\hline Terbutryn & $1.0-12$ & $0.5-59$ & $10-24$ & $5.0-12$ & 2.0 & 1.0 & $2.0-4.0$ & $1.0-2.0$ & $0.8-3.6$ & $0.4-18$ \\
\hline Cybutryn & $0.5-5.9$ & $0.5-59$ & $5.0-12$ & $5.0-12$ & 1.0 & 1.0 & $1.0-2.0$ & $1.0-2.0$ & $0.4-1.8$ & $0.4-18$ \\
\hline Terbuthylazine & $0.5-5.9$ & $0.5-59$ & $5.0-12$ & $5.0-12$ & 1.0 & 1.0 & $1.0-2.0$ & $1.0-2.0$ & $0.4-1.8$ & $0.4-18$ \\
\hline Carbendazim & $0.5-5.9$ & $0.5-59$ & $5.0-12$ & $5.0-12$ & 1.0 & 1.0 & $1.0-2.0$ & $1.0-2.0$ & $0.4-1.8$ & $0.4-18$ \\
\hline IPBC & $4.9-59$ & $9.7-120$ & $45-120$ & $90-230$ & $6.0-9.0$ & $12-19$ & $6.0-18$ & $12-35$ & $3.9-18$ & $7.7-37$ \\
\hline Thiabendazole & $0.5-5.9$ & $0.5-5.9$ & $5.0-12$ & $5.0-12$ & 1.0 & 1.0 & $1.0-2.0$ & $1.0-2.0$ & $0.4-1.8$ & $0.4-18$ \\
\hline Tebuconazole & $1.0-12$ & $0.5-5.9$ & $10-24$ & $5.0-12$ & 2.0 & 1.0 & $2.0-4.0$ & $1.0-2.0$ & $0.8-3.6$ & $0.4-18$ \\
\hline Mecoprop & $7.3-89$ & $9.7-120$ & $68-180$ & $90-230$ & $9.0-14$ & $12-19$ & $9.0-27$ & $12-35$ & $3.9-18$ & $7.7-37$ \\
\hline
\end{tabular}


Table S12 Total concentrations (dissolved + particulate fractions) of biocides in different urban waters and surface waters in ng/L

\begin{tabular}{|c|c|c|c|c|c|c|c|c|c|c|c|c|c|c|c|c|c|c|}
\hline \multirow[b]{2}{*}{ Sampling campaign } & \multicolumn{3}{|c|}{$\begin{array}{c}\text { Total atmospheric } \\
\text { fallout (ng/L) }\end{array}$} & \multicolumn{3}{|c|}{ Surface waters (ng/L) } & \multicolumn{3}{|c|}{$\begin{array}{c}\begin{array}{c}\text { WWTP effluents } \\
\text { (ng/L) }\end{array} \\
\end{array}$} & \multicolumn{3}{|c|}{$\begin{array}{c}\begin{array}{c}\text { WWTP influents } \\
\text { (ng/L) }\end{array} \\
\end{array}$} & \multicolumn{3}{|c|}{$\operatorname{CSOs}(n g / L)$} & \multicolumn{3}{|c|}{ Stormwater (ng/L) } \\
\hline & 1 & 2 & 3 & 1 & 2 & 3 & 1 & 2 & 3 & 1 & 2 & 3 & 1 & 2 & 3 & 1 & 2 & 3 \\
\hline Diuron & 1.2 & 0.8 & $<\mathrm{LOQ}$ & 20 & 3.5 & 2.8 & 38 & 11 & 31 & 35 & 3.4 & 23 & 910 & 150 & 200 & 32 & 47 & 17 \\
\hline Isoproturon & 0.04 & 0. & 0.02 & 1.9 & 0.5 & $<\mathrm{LOQ}$ & 0.9 & 0.8 & $<\mathrm{LOQ}$ & 1.1 & 1.1 & $<\mathrm{LOQ}$ & 8.4 & 1.5 & 2.0 & 1.0 & 3.1 & 2.8 \\
\hline MIT & 39 & 110 & 61 & 14 & 17 & $<\mathrm{LOQ}$ & 110 & 65 & 39 & 860 & 430 & 350 & 85 & 60 & 8.9 & 170 & 76 & 96 \\
\hline BIT & 2.7 & $<\mathrm{LOQ}$ & $<\mathrm{LOQ}$ & 2.4 & $<\mathrm{LOQ}$ & 2.5 & 55 & 48 & 26 & 450 & 660 & 300 & 6.2 & 18 & 34 & 200 & 43 & 39 \\
\hline CMIT & 57 & 30 & 5.6 & $<\mathrm{LOD}$ & $<\mathrm{LOD}$ & $<\mathrm{LOQ}$ & $<\mathrm{LOQ}$ & $<\mathrm{LOQ}$ & $<\mathrm{LOQ}$ & $<\mathrm{LOD}$ & $<\mathrm{LOD}$ & $<\mathrm{LOQ}$ & 40 & 130 & 30 & 60 & 21 & 47 \\
\hline OIT & 1.6 & 3.6 & 1.7 & $<\mathrm{LOQ}$ & $<\mathrm{LOQ}$ & $<\mathrm{LOQ}$ & 1.4 & $<\mathrm{LOD}$ & $<\mathrm{LOD}$ & 7.4 & 3.2 & 1.1 & 66 & 22 & 34 & 11 & 5.9 & 8.1 \\
\hline DCOIT & 0.9 & 1.4 & 1.1 & 1.6 & 1.5 & 1.7 & 1.3 & 4.6 & 3.3 & 6.6 & $<\mathrm{LOD}$ & 10 & - & 7.8 & 6.0 & $<\mathrm{LOD}$ & $<\mathrm{LOD}$ & 70 \\
\hline BZK C12 & 90 & 40 & 100 & 200 & 40 & 1 & 100 & 600 & 300 & 500 & 700 & 2000 & 1000 & 6000 & 5000 & 5000 & 20000 & 10000 \\
\hline BZK C14 & 70 & 30 & 20 & 70 & 60 & 0.5 & 3 & 300 & 90 & 20 & 500 & 300 & 200 & 5000 & 4000 & 2000 & 300 & 4000 \\
\hline BZK C16 & 20 & 0.3 & $<\mathrm{LOQ}$ & 40 & 40 & 0.2 & 1 & 80 & $<$ LOQ & 4 & 200 & 4 & 200 & 700 & 200 & 80 & 300 & 400 \\
\hline Terbutryn & 0.1 & 1.0 & 1.1 & 2.8 & 1.2 & 1.1 & 16 & 11 & 12 & 11 & 6.2 & $<\mathrm{LOQ}$ & 79 & 61 & 55 & 45 & 30 & 17 \\
\hline Cybutryn & $<\mathrm{LOQ}$ & $<\mathrm{LOD}$ & $<\mathrm{LOD}$ & $<\mathrm{LOQ}$ & 0.2 & $<\mathrm{LOQ}$ & $<\mathrm{LOD}$ & $<\mathrm{LOQ}$ & $<$ LOQ & $<\mathrm{LOD}$ & $<\mathrm{LOD}$ & $<\mathrm{LOD}$ & 4.1 & $<\mathrm{LOD}$ & $<\mathrm{LOD}$ & 3.2 & 0.2 & $<\mathrm{LOQ}$ \\
\hline Terbuthylazine & 0.03 & 38 & 0.01 & 52 & 3.8 & 2.5 & $<\mathrm{LOQ}$ & 2.2 & 1.1 & $<\mathrm{LOQ}$ & 2.1 & 2.1 & 11 & 0.2 & 1.3 & 17 & 15 & 21 \\
\hline Carbendazim & 0.1 & 3.5 & 0.03 & 8.4 & 3.7 & 7.4 & 3.5 & 9.8 & 22 & $<$ LOQ & 12 & 36 & 180 & 66 & 54 & 42 & 51 & 49 \\
\hline IPBC & 4.2 & 13 & 5.4 & 1.8 & 0.7 & 1.0 & 1.5 & 2.4 & 1.7 & $<\mathrm{LOQ}$ & 3.9 & 5.1 & $<\mathrm{LOQ}$ & $<\mathrm{LOQ}$ & $<\mathrm{LOQ}$ & 4.2 & 3.6 & 24 \\
\hline Thiabendazole & 0.1 & 0.04 & 0.1 & 1.1 & 0.9 & 0.01 & 19 & 13 & 14 & 10 & 14 & 3.2 & 13 & 1.5 & 1.6 & 11 & 11 & 7.4 \\
\hline Tebuconazole & 0.7 & 10 & 0.7 & 160 & 6.3 & 2.2 & 5.9 & 6.4 & 4.2 & 3.2 & 9.0 & 1.0 & 50 & 34 & 33 & 21 & 27 & 31 \\
\hline Mecoprop & $<\mathrm{LOD}$ & 0.1 & $<\mathrm{LOQ}$ & 22 & 11 & $<\mathrm{LOD}$ & 8.9 & 24 & $<\mathrm{LOD}$ & $<\mathrm{LOD}$ & $<\mathrm{LOD}$ & $<\mathrm{LOD}$ & 147 & 85 & 16 & 190 & 840 & 470 \\
\hline
\end{tabular}


Table S13 Biocide proportions (\%) in the particulate fractions

\begin{tabular}{|c|c|c|c|c|c|c|c|c|c|c|c|c|c|c|c|c|c|c|}
\hline \multirow[b]{2}{*}{$\begin{array}{l}\text { Sampling } \\
\text { campaign }\end{array}$} & \multicolumn{3}{|c|}{ Rain water } & \multicolumn{3}{|c|}{ Surface waters } & \multicolumn{3}{|c|}{$\begin{array}{c}\text { WWTP } \\
\text { effluents }\end{array}$} & \multicolumn{3}{|c|}{$\begin{array}{c}\text { WWTP } \\
\text { influents }\end{array}$} & \multicolumn{3}{|c|}{ CSOs } & \multicolumn{3}{|c|}{ Stormwater } \\
\hline & 1 & 2 & 3 & 1 & 2 & 3 & 1 & 2 & 3 & 1 & 2 & 3 & 1 & 2 & 3 & 1 & 2 & 3 \\
\hline Diuron & 5 & 8 & - & 1 & 2 & 2 & 0 & 1 & 0 & 20 & 7 & 2 & 1 & 1 & 1 & 1 & 1 & 5 \\
\hline Isoproturon & 28 & 12 & 14 & 5 & 3 & - & 1 & 3 & & 9 & 4 & - & 7 & 14 & 69 & 30 & 9 & 10 \\
\hline MIT & 2 & 1 & 1 & 100 & 18 & 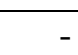 & 0 & 0 & 0 & 0 & 0 & 0 & 8 & 16 & 100 & 8 & 15 & 11 \\
\hline BIT & 3 & - & & 100 & - & 100 & 2 & 2 & 1 & 10 & 2 & 7 & 100 & 100 & 21 & 31 & 100 & 100 \\
\hline CMIT & 24 & 28 & 0 & - & - & - & - & - & - & - & - & - & 8 & 7 & 0 & 19 & 30 & 15 \\
\hline OIT & 4 & 2 & 4 & - & - & - & 4 & - & - & 45 & 7 & 43 & 17 & 8 & 10 & 28 & 21 & 19 \\
\hline DCOIT & 12 & 5 & 0 & 0 & 0 & 0 & 0 & 0 & 0 & 13 & & 0 & - & 0 & 0 & - & - & $\mathrm{c}$ \\
\hline BZK C12 & 19 & 22 & 14 & 80 & 1 & 12 & 2 & 28 & 6 & 65 & 13 & 3 & 43 & 0 & 14 & 2 & 15 & 27 \\
\hline BZK C14 & 1 & 26 & 5 & 12 & 1 & 6 & 12 & 12 & 6 & 60 & 5 & 9 & 6 & 0 & 9 & 1 & 23 & 23 \\
\hline BZK C16 & 3 & 5 & - & 6 & 2 & 3 & 100 & 2 & & 100 & 1 & 100 & 2 & 0 & 5 & 5 & 1 & 1 \\
\hline Terbutryn & 29 & 1 & 3 & 7 & 1 & 48 & 0 & 0 & 0 & 1 & 1 & - & 4 & 1 & 3 & 2 & 2 & 5 \\
\hline Cybutryn & - & - & - & - & 10 & - & - & - & - & - & - & - & 2 & - & - & 6 & 44 & . \\
\hline Terbuthylazine & 24 & 0 & 9 & 1 & 1 & 0 & - & 1 & 2 & - & 2 & 4 & 2 & 37 & 80 & 2 & 2 & 3 \\
\hline Carbendazim & 33 & 2 & 16 & 3 & 0 & 0 & 0 & 0 & 0 & - & 0 & 0 & 4 & 2 & 3 & 3 & 2 & 10 \\
\hline IPBC & 27 & 0 & 5 & 100 & 100 & 100 & 100 & 100 & 100 & - & 100 & 100 & - & - & & 100 & 100 & 18 \\
\hline Thiabendazole & 34 & 100 & 25 & 4 & 2 & 100 & 0 & 0 & 0 & 4 & 2 & 15 & 22 & 81 & 82 & 8 & 6 & 19 \\
\hline Tebuconazole & 18 & 3 & 9 & 5 & 5 & 10 & 0 & 3 & 0 & 3 & 1 & 8 & 11 & 4 & 7 & 8 & 7 & 14 \\
\hline Mecoprop & - & 100 & - & 0 & 0 & - & 0 & 0 & - & - & - & - & 1 & 1 & 10 & 1 & 1 & $\mathrm{c}$ \\
\hline
\end{tabular}

- indicates that proportions were not calculated (biocides not quantified in any fraction) 